Portland State University

PDXScholar

\title{
Global Time-Independent Agent-Based Simulation for Transactive Energy System Dispatch and Schedule Forecasting
}

Shawn Aaron Chandler Portland State University

Follow this and additional works at: https://pdxscholar.library.pdx.edu/open_access_etds

Part of the Energy Systems Commons, and the Power and Energy Commons Let us know how access to this document benefits you.

\section{Recommended Citation}

Chandler, Shawn Aaron, "Global Time-Independent Agent-Based Simulation for Transactive Energy System Dispatch and Schedule Forecasting" (2015). Dissertations and Theses. Paper 2212.

https://doi.org/10.15760/etd.2209

This Thesis is brought to you for free and open access. It has been accepted for inclusion in Dissertations and Theses by an authorized administrator of PDXScholar. Please contact us if we can make this document more accessible: pdxscholar@pdx.edu. 
Global Time-Independent Agent-Based Simulation for Transactive Energy System Dispatch and Schedule Forecasting

\author{
by \\ Shawn Aaron Chandler
}

A thesis submitted in partial fulfillment of the requirements for the degree of

\author{
Master of Science \\ in \\ Systems Science
}

Thesis Committee:

Wayne Wakeland, Chair

Jeffrey Fletcher

Robert B. Bass

\title{
Portland State University 2015
}


(C) 2015 Shawn Aaron Chandler 


\begin{abstract}
Electricity service providers (ESP) worldwide have increased their interest in the use of electrical distribution, transmission, generation, storage, and responsive load resources as integrated systems. Referred to commonly as "smart grid," their interest is driven by widespread goals to improve the operations, management and control of large-scale power systems. In this thesis I provide research into a novel agent-based simulation (ABS) approach for exploring smart grid system (SGS) dispatch, schedule forecasting and resource coordination. I model an electrical grid and its assets as an adaptive ABS, assigning an agent construct to every SGS resource including demand response, energy storage, and distributed generation assets. Importantly, real time is represented as an environment variable within the simulation, such that each resource is characterized temporally by multiple agents that reside in different times. The simulation contains at least as many agents per resource as there are time intervals being investigated. These agents may communicate with each other during the simulation, but only agents assigned to represent the same unique resource may exchange information between time periods. Thus, confined within each time interval, each resource agent may also interact with other resource agents. As with any agent-based model, the agents may also interact with the environment, in this case, containing forecasted environment, load and price information specific to each time interval. The resulting model is a time-independent global approach capable of: (1) capturing time-variant local grid conditions and distribution grid load balancing constraints;
\end{abstract}


(2) capturing time-variant resource availability and price constraints, and finally, (3) simulating efficient unit-commitment real-time dispatches and schedule forecasts considering time-variant forecasted transactive market prices. This thesis details the need for such a system, discusses the form of the ABS, and analyzes the predictive behavior of the model through a critical lens by applying the resulting proof-of-concept simulation to a set of comprehensive validation scenarios. The resulting analysis demonstrates $\mathrm{ABS}$ as an effective tool for real-time dispatch and SGS schedule forecasting as applied to research, short-term economic operations planning and transactive systems alike. The model is shown to converge on economic opportunities regardless of the price or load-forecast shape and to correctly perform least-cost dispatch and schedule forecasting functionality. 


\section{Dedication}

I would like to dedicate this work to my wife, Helen, daughter, Marianne, and son, Charles. 


\section{Acknowledgments}

I would like to acknowledge my thesis committee and the many professors who have influenced my work, with special consideration given to Dr. Wayne Wakeland who has dedicated countless hours reading my lengthy papers and offering wellconstructed feedback essential to my work. I also want to specially thank Dr. Jeff Fletcher for his perspectives on computational intelligence and game theory, and Dr. Bob Bass for his insights on applications for modeling within electrical engineering. I acknowledge my academic and professional colleagues Peter Banda, Mike Hoffman, Joshua Hughes, Alexandra Nielsen, J. R. Rinaldi, Dr. Wayne Lei and Max Valdez for their thoughts regarding my work on smart grid. I would also like to thank Michael Bohrer-Clancy for his editorial expertise. Finally, I acknowledge my colleague and friend Larry Beckett, whose advice and technical influence over the years have been instrumental in my success. 


\section{Table of Contents}

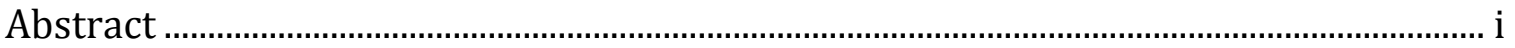

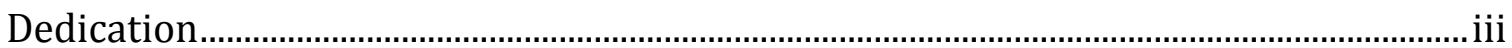

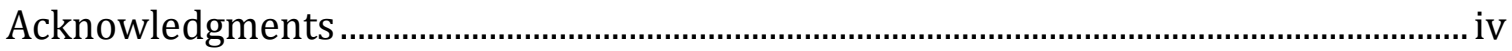

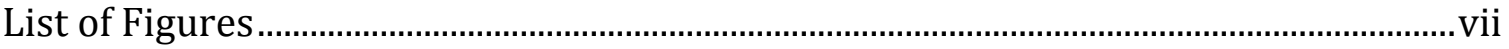

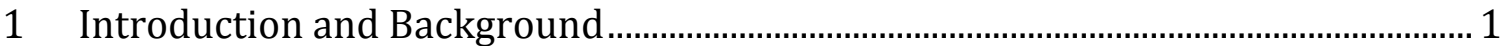

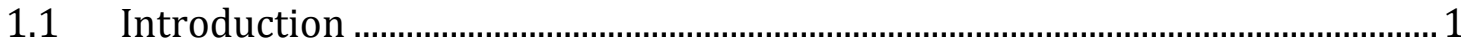

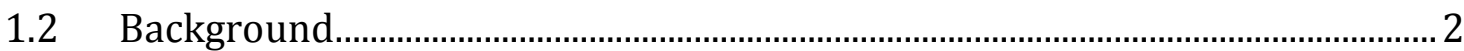

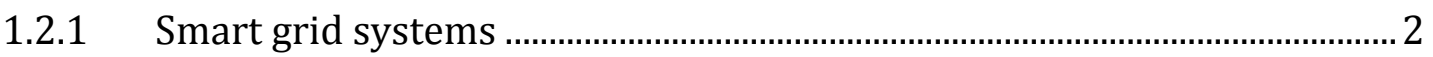

1.2.1.1 Advanced metering infrastructure ............................................................... 3

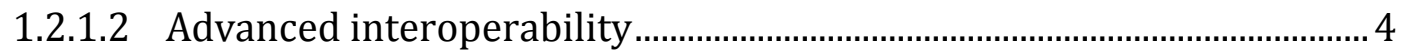

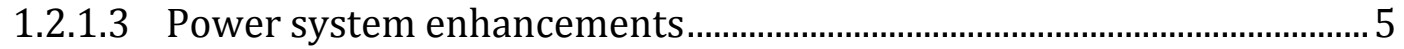

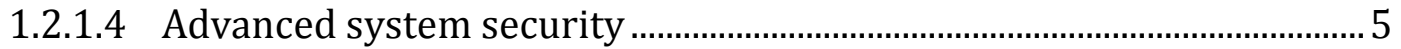

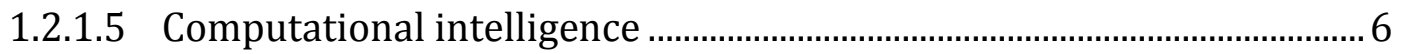

1.2.2 Security-constrained economic dispatch ........................................................ 7

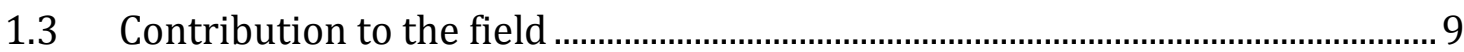

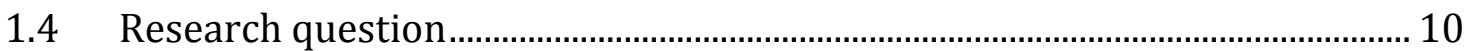

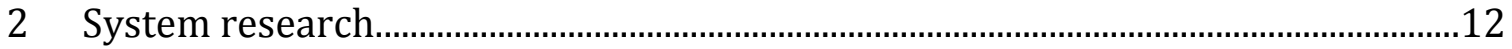

2.1 Electricity service provider functionality …........................................................ 12

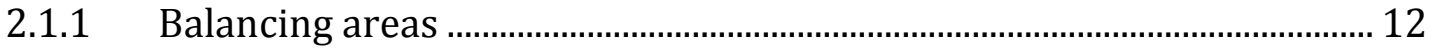

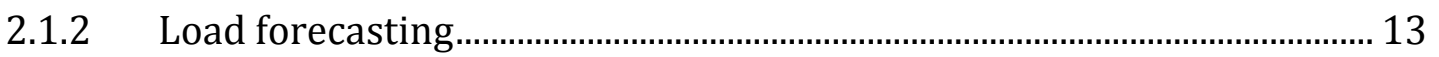

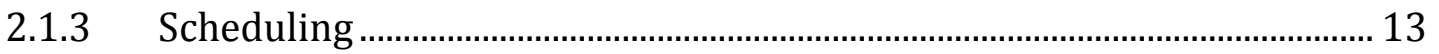

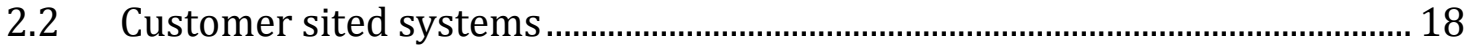

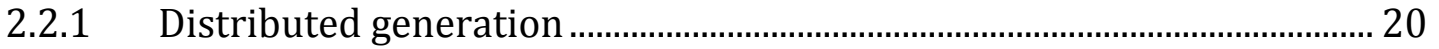

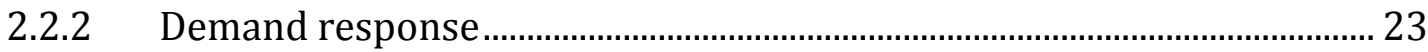

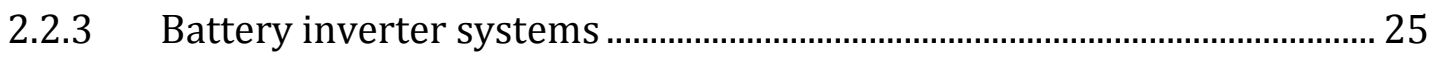

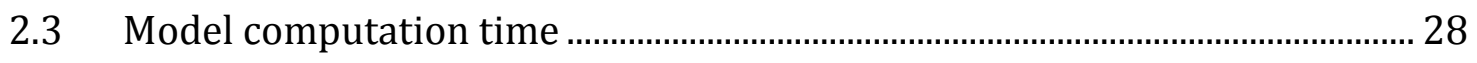

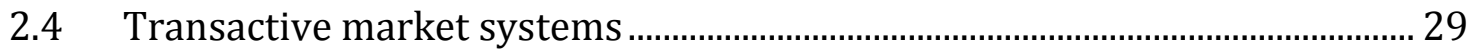

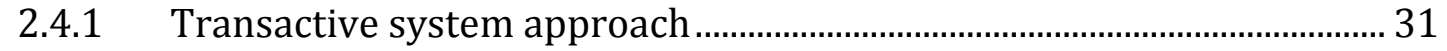

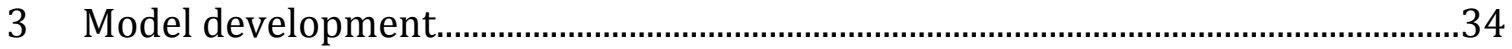

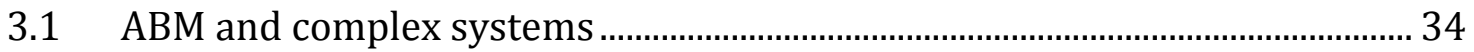




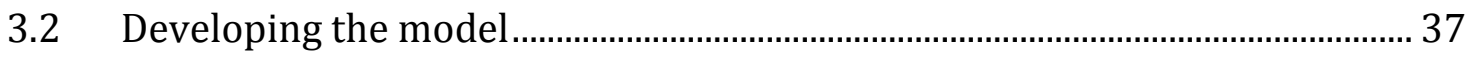

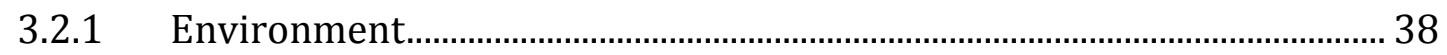

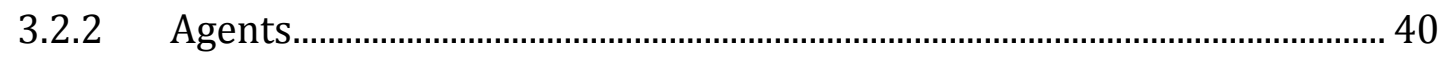

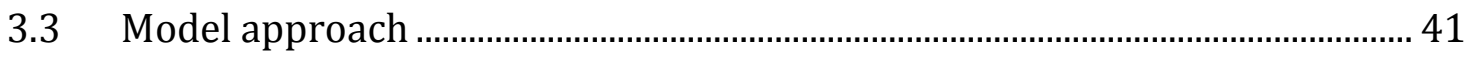

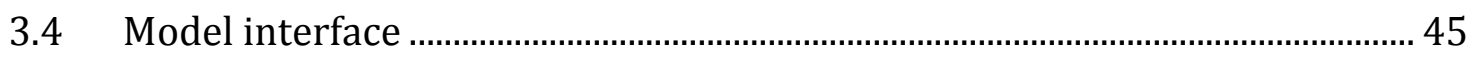

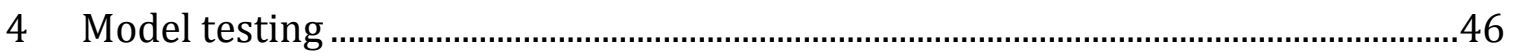

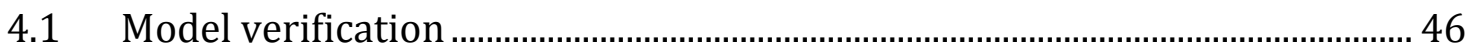

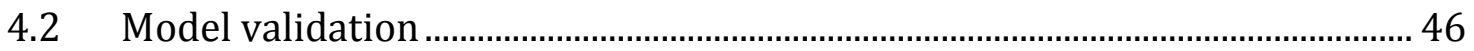

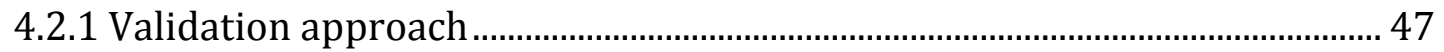

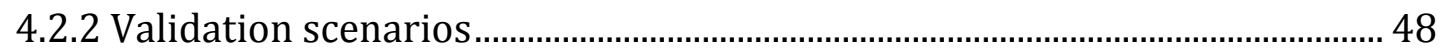

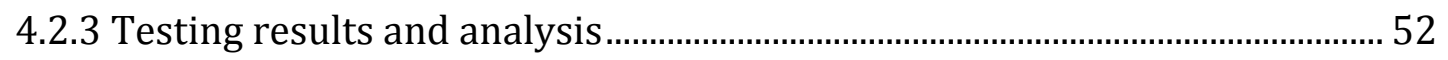

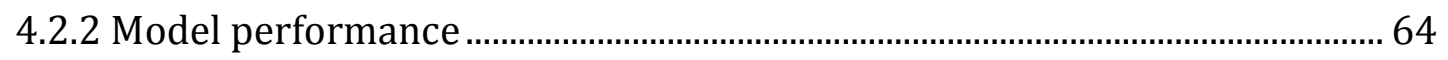

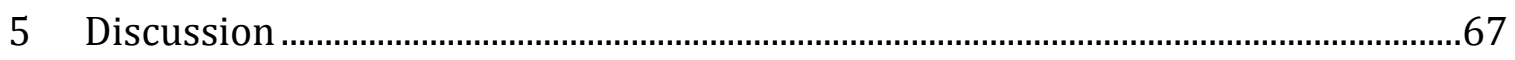

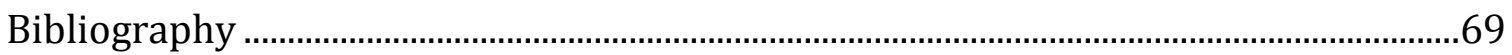

Appendix: Validation Scenario Feature Matrix ……..........................................................75 


\section{List of Figures}

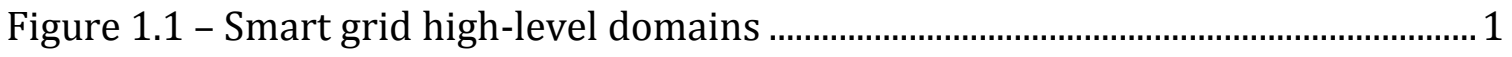

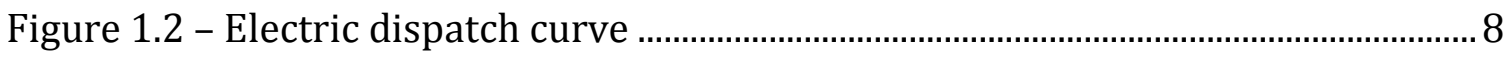

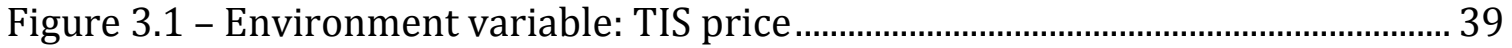

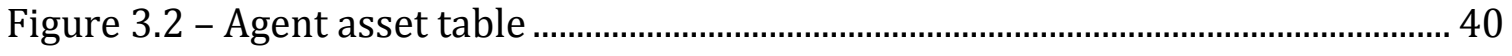

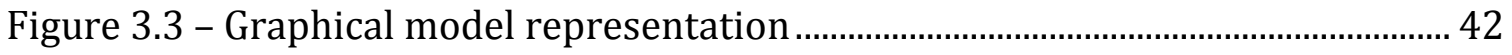

Figure 3.4 - Agent behavior: Calculation of economic dispatch potential ................... 43

Figure 3.5 - Agent behavior: Calculation of rank for dispatch........................................ 44

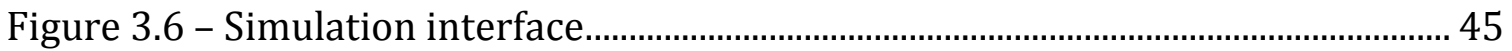

Figure 4.1 - Validation scenario 1: Model results.................................................................. 53

Figure 4.2 - Validation scenario 2: Model settings and results ...................................... 54

Figure 4.3 - Validation scenario 3: TIS price and model results ..................................... 55

Figure 4.4 - Validation scenario 4: Model settings .............................................................. 56

Figure 4.5 - Validation scenario 4: TIS price and model results ..................................... 57

Figure 4.6 - Validation scenario 5: Model settings ........................................................... 58

Figure 4.7 - Validation scenario 5: TIS price and model results ..................................... 58

Figure 4.8 - Validation scenario 6: Model settings................................................................. 59

Figure 4.9 - Validation scenario 6: TIS price and model results ...................................... 60

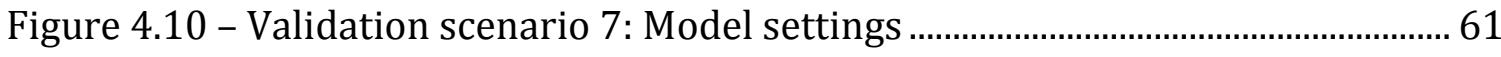

Figure 4.11 - Validation scenario 7: TIS price and model results .................................. 62

Figure 4.12 - Validation scenario 8: TIS price and model results .................................. 63

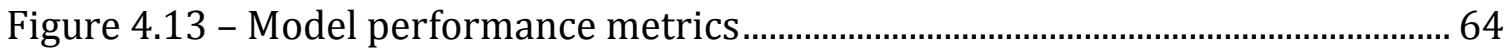

Figure 4.14 - Model performance: Simulation speed by validation test........................ 65

Figure 4.15 - Model performance: CPU usage metrics by validation test.................... 65

Figure 4.16 - Model performance: Application scaling ......................................................... 66 


\section{Introduction and Background}

\subsection{Introduction}

The electric power grid is the most expansive man-made object on Earth, being labeled the "the world's largest and most complex machine" [1]. While the basic tenets of the electrical system have remained unchanged for the last 100 years, numerous aspects of its operation have evolved quickly over the last ten years. Many new technologies concerning system automation, reliability, and control have been developed, and others adapted to enable what is now commonly referred to as smart grid. Smart grid systems (SGS) may generally be considered a collection of technologies or resources embodying behavioral characteristics that benefit the power grid's electricity service providers (ESP), system operators, or consumers, be it through efficiency from distributed intelligence, energy balancing, enabling renewable energy resource integration, or many other possible economic or reliability related effects. The

Smart Grid Interoperability

Panel, a smart grid operations

focused industry group in

North America, describes the high-level smart grid "domain model," shown in Figure 1.1,

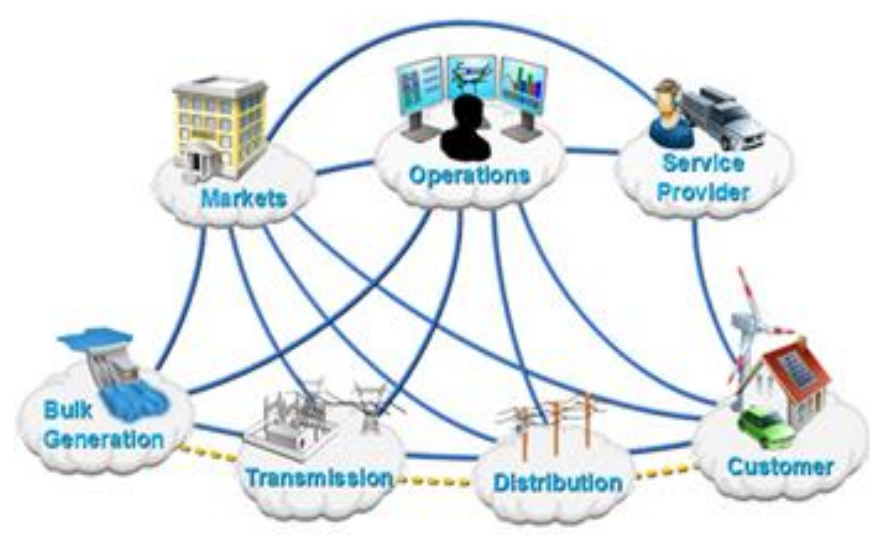

Figure 1.1 - Smart grid high-level domains [10] as a combination of electrical and high-speed communication links between industry business entities, markets, 
and customers. Integration of these domain level systems is a new challenge for ESP and other grid operations organizations, creating a need for management software applications [2]. This thesis uses agent-based simulation (ABS) to explore one such need in an emerging real-time power operations market design called a transactive energy system. A transactive energy system seeks to monetize, or otherwise value, each of the responsive SGS within the grid, whether they concern transmission, distribution, generation, or load. Transactive systems (TS) are envisioned to improve electrical interconnect reliability and optimize grid economic efficiency. TS will be discussed in detail in Section 2.4.

\subsection{Background}

\subsubsection{Smart grid systems}

A smart grid is composed of a variety of electrical system technologies and resources, all of which are intended to work together as an integrated system. Given an underlying need for high-speed communications at the core of SGS functionality, it may be said that the potential for the smart grid began with the advent of the Internet. Just as computational advances became a driver for integrating social systems at scale within computer networks, similarly applied computing advances have allowed the integration of ESP, consumer and engineering systems to become a reality [3]. The smart grid may be generalized to contain the following high-level systematically integrated components: advanced metering 
infrastructure, advanced interoperability, power system enhancements, system security, and computational intelligence [3] [4].

\subsubsection{Advanced metering infrastructure}

Advanced metering infrastructure (AMI) refers to electrical meters which capture much more granular time-based power data than their analog predecessors; they are often considered the underlying basic component for smart grid systems [4] [5]. Data collected from AMI is generally called interval data, referring to the power information measured as either energy usage over specific intervals of time (e.g., kilowatt-hours [kWh] or megawatt-hours [MWh]), or instantaneous draw of power at a specific time (e.g., watts, kilowatts [kW], or megawatts [MW]). Phasor measurement unit (PMU) hardware, a relatively new type of AMI device (commonly called a synchrophasor), measures voltage and current in real-time using timestamped messages synchronized with a satellite clock. These high-quality measurements from the system can be used to inform operations across an electric grid (e.g., real-time situational awareness and disturbance analysis, high-precision state estimation, and remedial action schemes). Altogether, AMI captures power data from PMUs, customer meters and Supervisory Control and Data Acquisition (SCADA) connected resources in less than a second to every few minutes, allowing for ESP to trend system behavior and customer usage. AMI may also permit twoway communication between the customer and the ESP enabling net-metering [6]. Net-metering means to monitor two-way power flows, that is, the net of the energy used by a customer minus the energy dispatched to the grid from that customer's 
own generation SGS resources. Since power systems have been traditionally engineered to allow power flow in only one direction-from centralized generation plants to transmission systems, onto distribution systems, and then to customer premises-AMI net metering has compelled a fundamental change in the construction of the electrical grid [4]. Thus, some SGS may be constructed with an expectation that their generation is located within the distribution grid (e.g., commercial-scale wind, solar, and distributed standby-generation in industrial and large commercial sites). Here, AMI is important for system operation as it may deliver up-to-date information in near-real-time for model consideration, allowing for forecasting and scheduling process inputs using only the most recently collected information.

\subsubsection{Advanced interoperability}

Interoperability is a primary goal of smart grid, referring to the integration of the many systems that ESP, customers, and transmission providers own and manage [3]. Interoperability here refers to the exchange of meaningful, actionable information between two or more systems across system boundaries (e.g., distribution outage systems exchanging information with customer service systems in the case of an electrical fault) or within system boundaries (e.g., between relays from different manufacturers accessing the same process bus) [7]. Interoperability also requires a shared understanding of the exchanged information, an agreed expectation for the response to the information exchanged, and a requisite quality of service including reliability, fidelity, and security [2]. Utilities may choose a formal 
approach to information systems compatibility, developing distribution system architecture based on IEC-61850 substation automation and IEC-61970 common information models, or use common protocols, such as DNP3 or MODBUS to manage interoperability [8] [9]. Importantly, transactive systems also require communications and interoperability throughout many other layers of grid infrastructure using standardized protocols (e.g., "OpenADR," “Multispeak," “ICCP," and "Zigbee") [10] [11].

\subsubsection{Power system enhancements}

The smart grid ideally contains control systems, resources, and technologies which may increase reliability and system efficiency when integrated together [4]. These may include, but are not limited to, distributed generation (e.g., wind and solar), demand side-management (e.g., direct load control and energy efficiency), energy storage, distribution system enhancements (e.g., voltage optimization, automated reclosers and switches, and other power management equipment), and grid state visualization tools [3] [12] [13] [14]. Power system enhancements of interest here have characteristics which will be discussed fully in Section 2.2.

\subsubsection{Advanced system security}

System security is a primary aspect of smart grid insomuch as it is necessary to protect infrastructure from cyber threats: as electronic systems to manage and control the grid are further integrated, cyber threats and vulnerabilities likewise increase from exposure. Efforts to manage system security are focused on 
confidentiality, system integrity, and system availability [15]. Electronic system perimeter protection, such as that defined by the U.S. National Energy Regulatory Commission (NERC) within their cybersecurity information protection (CIP) standards, may be used to help define the availability of a system, such that elements in a smart grid may become "untrusted" should a security interface fail. Security is important to aspects of modeling for real-time markets since a system may recognize a threat or vulnerability and remove a SGS resource from service.

\subsubsection{Computational intelligence}

Computational intelligence (CI) is the study of adaptive systems that supports or assists intelligent behavior in complex, dynamic, and unpredictable environments [16]. As such, CI may be considered the "smart" in the smart grid. Much of the existing CI for the grid deals with situational awareness and intelligent control; $\mathrm{CI}$ is critical for efficient and reliable system dispatch and managing electrical system behavior including characterizing responses to power quality issues or faults in the transmission or distribution system, SCADA resource control, and remedial actions in the transmission system [13] [16] [17]. CI search algorithms may also effectively manage price responsive energy flow, such as with time-of-day pricing or with electric vehicle-to-grid ESP integration [16] [18]. CI may also be used to predict potential conditions in the grid and aid in the scheduling of generation and demand resources [16] [18] [19]. Forecasting and scheduling may be accomplished using a variety of CI tools, including but not limited to particle swarm optimization (PSO); mixed integer linear programming (MILP); dynamic 
programming (DP); artificial neural networks (ANN); genetic algorithms and evolutionary programming (GA and EP, respectively); and most recently, ABS [12] [16] [17] [18] [20] [21] [22]. Clearly, there are many possible applications of CI within electric system operations. In the context of this thesis, $\mathrm{CI}$ is of interest based on the need for automated market dispatch and forecasting using real-time system inputs and transactive control incentive signals. Transactive control will be addressed in detail in Section 2.4.

\subsubsection{Security-constrained economic dispatch}

In the context of this research, security-constrained economic dispatch (SCED) is the process of developing a schedule of generation and load reduction from available ESP and market system resources, resulting in the lowest cost reliable resource portfolio to meet the highest forecasted electrical demand in the system for a specific forecasting period. SCED calculation is notably different than optimal power flow (OPF) calculations, which determines the optimal flow of generation through a transmission grid considering electrical factors. While optimization of generation resources concerning power flow is generally a mathematically non-convex optimization problem with many local minima, SCED concerning power operations may be simplified to what is known as a constrained supply stack [23] [24]. A supply stack depends on the variable operating costs-or market prices-of electric power generators through time, which is used to determine which units are elected by the power marketing business area of an ESP to meet the demand for electricity. While constraints around the use of these assets 
must be accounted for, the generation resources with the lowest bid operating costs will be dispatched first, while other generation (with larger variable costs) is dispatched in the order of cost as the demand for electricity increases [25]. An example is shown in Figure 1.2.

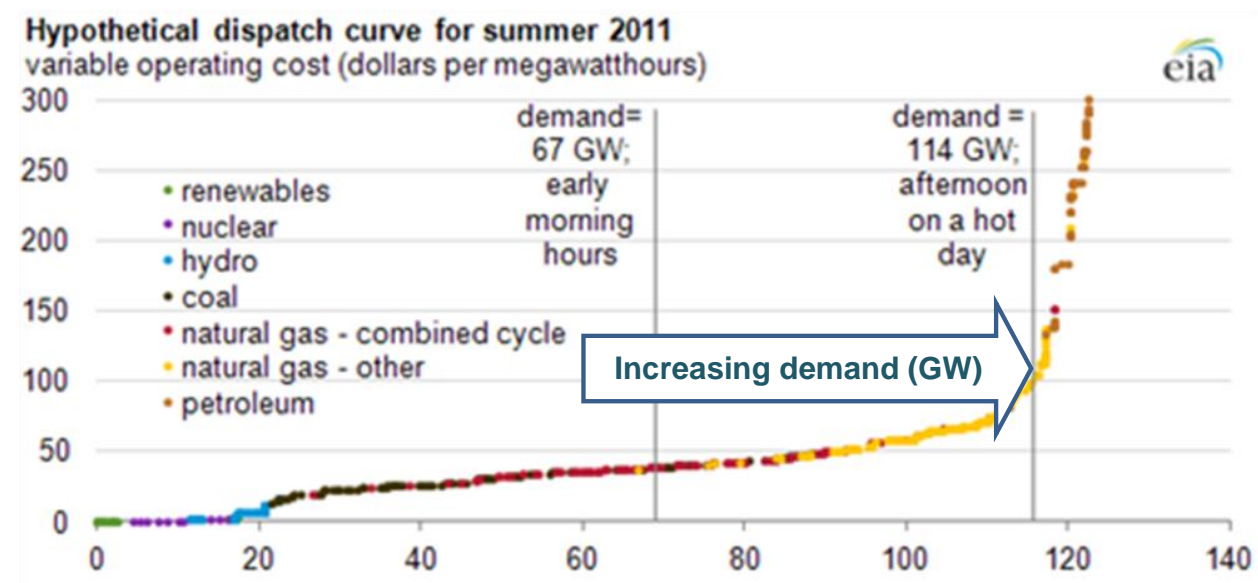

Figure 1.2 - Electric dispatch curve [25]. As demand increases, the cost to serve the load increases. Least-cost sources (e.g., renewables, nuclear, and hydro) are shown to serve load first, then higher-cost resources (e.g., natural gas and petroleum) last.

Notably, with SGS, the dispatch problem also encompasses responsive distribution, load, and generation resources, further expanding the dispatch problem. Real-time dispatch thus has some influence over the control of the physical system, inasmuch as generation should be dispatched in approximately equal amounts to the forecasted load. Moreover, precise consideration must be given to customer preferences for time-of-use constrained or demand-limiting systems. Finally, while distribution operators have used manual breakers and switches to protect electrical systems in the past, now, greater component automation allows for real-time management and physical configuration of utility 
assets. These constraints are not generally considered a component of SCED, but with the advent of integration between customer systems, market systems, and electrical systems, it is vital that SCED consider SGS resources and their capabilities [3] [13] [18].

\subsection{Contribution to the field}

Smart grid systems pose significant challenges to ESP operation because short-term market planning, distributed system control (i.e., integrated customer and utility systems), and transmission operations involve integration of traditionally separate grid management disciplines, namely market system economic planning, grid distribution system management, and grid interconnect system management, respectively. In particular, research has noted the benefits of using "agents" to build more capable networks with intelligent aspects for decision support in terms of context [26], including comprehensive research specific to agent-based grid control [22]. Although several recent studies address smart grid control at the electrical, market, and customer system layers as an integrated concern [12] [22] [27] [71], others have focused either on market scheduling [28] [29] [30] [31] or electrical systems modeling independent of the market [32] [33] [34] [35] [36]. This divide in the research is likely drawn from subject matter differences, where economically-based smart grid interests have naturally focused on the market, and electrical engineering smart grid interests have focused on the grid dispatch control challenges. Likewise, in ESP power marketing operations, optimal market dispatch has been accepted as a resource availability and cost issue 
which is largely simplified as a stacked resource problem, while electrical system management is isolated as a system protection issue within ESP distribution engineering departments [70]. Notably, studies [12] and [71] applied a mix of realtime dispatch and short-term forecasting, but using a contextual high-level learning artificial neural network and linear programming approach, respectively. In summary, studies exploring the use of ABS and other methods are found to address dynamic constraints for each resource, but in simulated real-time, that is, as a simulation runs, it solves for one time-period's allocation of resources before moving to the next time-period of study. However, none are found to use ABS to mix real-time resource dispatch optimization with short-term forecast horizons and solve for all time-periods within the simulation in parallel (i.e., an integrated global time-independent system model). This thesis presents an ABS-based timeindependent method for generating real-time ESP transactive dispatch and SGS schedule forecasting solutions.

\subsection{Research question}

This research seeks to explore in detail my novel application of a timeindependent agent-based model (ABM) in the context of ESP SGS resource operations management as applied to transactive system dispatch and schedule forecasting functions. This work seeks to justify the design and development of the approach appropriate to this goal as follows: 
- emergent behavior due to dynamic systems interaction of SGS and feedforward demand-dependent cost functions is nontrivial and may be addressed using ABM;

- timing and control constraints for energy storage, automated demandresponse direct-load-control and distributed generation in combination with distribution feeder operations load balancing creates demanddependent operations limit functions which are nontrivial for determining SGS resource schedules, and which may be properly addressed using ABM;

- ABM may be used for SGS schedule forecasting, given that each SGS resource's price function is impacted by the continued use of each resource in terms of economic scarcity; and

- ABM provides timely advantages for solving SGS schedule forecasting, given that solutions using other methods may be both time consuming and computationally intensive, possibly preventing effective market participation for fast-response imbalance markets or emerging transactive energy markets. In order to participate in automated markets containing imbalance operations, such as those managed by the California Independent System Operator, the system needs to converge on a solution in less than four seconds. Transactive markets demonstrated in [50] are less stringent, and require the system to converge on a solution in less than five minutes. 


\section{System research}

\subsection{Electricity service provider functionality}

ESP are defined here to manage electrical power transmission, distribution, generation, and responsive customer-based SGS. Although many pursuits throughout an ESP enterprise business may be integrated in terms of smart grid, load forecasting, generation and SGS scheduling, and integration of customer-based systems are considered primary interests to this research.

\subsubsection{Balancing areas}

A balancing area is a bounded physical area of electric utility service. Inside and extending to the edge of the balancing area are the power lines, substations and transformation resources, and other distribution electrical infrastructure managed by an ESP with the responsibility for that balancing area. Also in the balancing area are the customers who create demand for electricity [37]. The balancing area is a chief concern due to the physical nature of the electrical grid: electricity must be used just as it is generated, or balanced, with little tolerance for error. A service provider has a responsibility to manage the electrical balance of supply and demand through the resources they own or operate, as well as the contracts for resources they enter into with third parties specific to certain times of use. Here, in order to demonstrate the modeling approach, a balancing area is identical to the microgrid studied in [12] and [71]. 


\subsubsection{Load forecasting}

Electricity that is used instantaneously inside the balancing area is referred to as demand or load. Forecasting, as it is defined here, refers to looking ahead and making a prediction about the states of SGS resources in time, as well as load. Load forecasting may be undertaken by a variety of methods, including but not limited to, artificial neural networks, fuzzy logic systems, evolutionary computing, linear regression, stochastic time series, exponential smoothing, applied Kalman filters, and ABS [20] [38] [39]. ESP generally split balancing area load into three general usage profiles for forecasting: residential, commercial business, and heavy industry [24]. This research will accommodate the load forecast in the ABS as a predetermined environment variable.

\subsubsection{Scheduling}

Scheduling is defined here as a means to allocate the use of SGS systems in response to expected system conditions including transmission-supplied power price and load. Notably, the economic term "price" is used here instead of the term "cost," since the model is intended to schedule for power operations (i.e., managing operations risk through market participation). Thus, a forecasted schedule is a prediction concerning the allocation of generation resources-market derived and owned - for future load conditions. Management of the schedule generally concerns the conditions that affect the availability and economics of generation: production curves, which provide the rate at which an owned generator may operate effectively based on fuel type and environmental variables; the cost of fuel, 
which affects the price of generation supplied from a unit; generator reliability, which affects the likelihood of a resource being available during a time of need; regulation, which may constrain availability; and customer preference, which affects the likelihood of dispatch of a distributed (local to the ESP) SGS resource [40].

The ESP is responsible for serving the entire load that originates inside the balancing area (i.e., matching the generation scheduled to the demand for electricity in real-time which maintains the system reliability) [40]. In both real-time and each future period, an ESP expects to allocate the total generation equivalent to the balancing area demand plus line losses for the system among available generation resources [41] [42]. This is called the power balance constraint:

$$
\sum_{i=1}^{n}\left(P_{G i}\right)-P_{D}-P_{L}=0
$$

where $P_{G i}=$ Power generated by the $\mathrm{i}^{\text {th }}$ available generation resource $P_{D}=$ Power demand expected in the balancing area grid $P_{L}=$ loss determinant for the grid at the total power supplied $n=$ number of resources generating power Equation 1 - Power balance constraint

Serving the load $P_{D}$ in Equation 1 may be considered an equality constraint for the model system, insomuch as the sum of operating SGS resources must be exactly equal to the load.

An ESP must also maintain the generation for each resource $P_{G i}$ within their operating characteristics, meaning that generation may not exceed or produce less 
generation than the maximum or minimum amount required for safe operation, as follows:

$$
P_{G i}^{\min } \leq P_{G i} \leq P_{G i}^{\max }
$$

$$
\begin{aligned}
& \text { where } P_{G i}^{\min }=\text { lower bound on generation output of resource } \mathrm{G}_{\mathrm{i}} \\
& P_{G i}^{\max }=\text { upper bound on generation output of resource } \mathrm{G}_{\mathrm{i}}
\end{aligned}
$$

Equation 2 - Real power output bounds [42]

The model will accommodate Equation 2 by using each resource at its maximum output to fulfill Equation 1, while constrained as the lowest-cost generation to meet the expected demand in the system. This can be expressed as an objective function for the model as follows:

$$
\operatorname{Min} \sum_{\boldsymbol{i}=\mathbf{1}}^{\boldsymbol{n}} F\left(P_{G i}\right)
$$

where $F\left(P_{G i}\right)=$ the price function of the $\mathrm{i}^{\text {th }}$ available generation resource, $P_{G i}$ $n=$ number of available resources

Equation 3 - Generation cost minimization function

It is assumed there is no penalty for using any SGS up to that resource's maximum generation contribution. Notably, this may not be the case with many plants, where large-scale generation systems may have a cost curve dependent on fuel type, head, temperature, ramp rates, and so forth, that penalizes for maximum possible plant output [43]. 
ESP scheduling may be summarized as meeting the power balance constraint and forecasting the unit commitment over time to meet functional criteria in Equations 1, 2, and 3. Here, the model output is intended to predict the schedule of generation for each future interval, meeting the basic ESP business need to supply electricity to the balancing area at the least overall cost.

Managing dispatch and scheduling is typically undertaken in two forms within an ESP: daily operations and real-time operations. In daily operations, the ESP forecast typically concerns hourly—or possibly sub-hourly—time slices, from the next 24 hours up to one week ahead. Participating in power markets or using owned generation resources, the ESP may economically match the expected load for each period of time to least-cost available generation as discussed in Section1.2.2. This forward schedule may then be matched to available transmission for each period through a contractual electronic clearing house, in North America called the Open Access Same Time Information System (OASIS). The decoupling of transmission operation from generation operation was managed through Federal Energy Regulatory Commission (FERC) Order 889. The regulation was generally intended to instill fairness in electricity markets while prompting private investment in independent power producer (IPP) facilities and transmission paths [46]. OASIS prevents ESP from favoring owned generation sources with similarly owned transmission line capacity contracts by publishing tariffs for transmission and creating fixed schedules for power flow [44] [45]. Power markets in North 
America thus depend on OASIS to remain viable and schedule transmission path use for forward transactions.

In contrast to daily operations, real-time operations are concerned only with the next incremental hour in real time, also called the prompt hour. This hour long operation horizon focuses on:

- dispatching power at any cost to serve the load as required to maintain grid system reliability;

- efficient market participation and risk mitigation;

- scheduling the dispatch of resources at least one hour ahead in anticipation of the most recent hourly load forecast; and

- maintaining stability with concerns for system limitations (e.g., lowerand upper-limits on generator real and reactive power, grid frequency management, bus voltage and angle, line and transformer current measure and angle, sets of transformer tap positions) [47].

Whereas real-time management of the market and transmission system will typically involve people, system limitations in the distribution system are generally managed by fault protection devices such as fuses and breakers, which automatically prevent damage and disconnect service when electrical reliability constraints (such as voltage or current limits) are violated or within certain tolerances. Real-time power operations practices may thus be divided between two functional ESP business groups: (1) real-time power marketing, which manages the buying, selling, and scheduling of power to transmission resources within sixty 
minutes or less of when it is thought to be needed, or sold off from previously committed sources and contracts; and (2) distribution and transmission operations, where system limitations are managed from a physical electrical perspective [24]. The model here will contain characteristics relevant to the real-time power marketing function, namely the load forecast, a real-time and day-ahead schedule horizon, and a dispatch schedule for generation and other SGS resources. Expected distribution and transmission losses pertaining to Equation 1 are assumed to be accounted for in the load forecast.

\subsection{Customer-sited systems}

Dispatch and schedule forecasting are traditionally considered separate functions within ESP operations, and while both are a challenge given traditional power system infrastructures, the management of operations becomes even more complex with the introduction of customer-sited systems. A smart grid may contain millions of additional points of control with multiple constraints per SGS resource. For example, responsive system integration with ESP operations requires careful constraint management as customer systems may not be generally interrupted without advance notice, severely limiting or removing altogether their real-time dispatch capability. Investigating the following business process for real-time power marketing is helpful to explore corresponding model functionality:

1. Determine projected load

The load curve, or forecast of load over time, is generally produced from a dedicated model. For system validation in Section 4.2.2, the load is 
predetermined according to an input file for each validation scenario. Load is defined in the model as an environmental variable.

2. Determine projected resource availability

Immediate dispatch availability may be determined from a SCADA communications link to owned resources or other communications network. Otherwise, contractual resources are assumed to run, such as OASIS scheduled generation purchased through bilateral contracts or forward power markets. Customer-sited responsive (grid-tied) system availability is broadly based on: customer preferences — such as time-ofday usage, when an SGS is restricted from use through customer intent; regulatory criteria — when a generator may not be used longer than a certain amount of time due to emissions restrictions for a geographic region; physical criteria-when a resource may not be used due to fuel availability, outage, safety, or other physical limitations; or economic criteria-when a resource dispatch opportunity is limited due to cost-ofuse when compared to other alternative resources.

Here, dispatch potential will first concern economic availability, meaning a SGS resource must first have a price less than the price for transmission supplied (contractually acquired) power to be considered. This will be discussed further in Sections 2.2.1 and 2.2.2.

Dispatch requires coordination among resources within an interval of interest so as not to create a load constraint violation. The schedule will 
also be limited to resources approximately equal to the amount of load in the grid, but not less than the amount of load in the grid pertaining to the power balance constraint in Equation 1. This will also be discussed in Sections 2.2.1 and 2.2.2.

3. Determine adjustments to contracts

Adjustment may sometimes occur in real-time dispatch if large-scale generation contracts have optionality, such as taking more or less of a firm contract for generation from an IPP for the next dispatch period [24]. Load that is served from contractually acquired transmission supplied generation is modeled here as a guaranteed alternative to local SGS resources without limitations (i.e., it is assumed there will be load following) as well as being available for all time periods within the forecast horizon.

\subsubsection{Distributed generation}

Distributed standby generation (DSG) is the term used to describe power generators which are owned by customers and distributed throughout an ESP balancing area. Heavy industry, many large commercial buildings, data centers, manufacturing facilities, and emergency response interests such as hospitals and military installations use DSG to avoid utility power quality issues and service interruptions, but the need for backup may arise only once or twice per year, if at all [37]. An ESP may request to connect these distributed plants together as a single resource, so as to control their generation in an aggregated manner, referred to as a 
virtual power plant (VPP). A VPP can act as a backup resource to provide emergency generation during peak load events [37]. Emerging market opportunities may also exist for both an ESP and the customer where DSG may be sold as ancillary services. Some ESP have agreements specific to "borrowing" these generation resources for a limited number of occurrences in order to meet peak loads or otherwise act as contingency reserves in exchange for some incentive or payment [37]. Since a DSG resource is strictly limited in its use, the dispatch strategy will change over time in terms of both availability and price, becoming a more valuable resource with each subsequent use [37]. Thus, DSG may be considered to have an increasing price function due to time-of-use restrictions [43]. This is notable since the model here must manage a benefit in one objective criteria —while price to use is low, usage is preferred— and account for decreasing benefit in another criteria - where availability is depleted over time and thus price may be increased to reflect resource scarcity. To account for this constraint, a new conditional inequality, shown in Equation 4, may be considered:

$$
\sum U_{j} \leq\left(\begin{array}{c}
\max \\
n
\end{array}\right)
$$

where $U_{j}=$ the usage at each time step $j$ for dispatch consideration

$U_{n}^{\max }=$ the upper bound for the total use of a SGS resource

\section{Equation 4 - Usage constraint function}

Other SGS resources under consideration here may also have use limits. The function may also measure the amount of time remaining to use the "remaining 
dispatches," similar to the method in which options are valued as they approach their expiration date. Consider the following expansion of Equation 3:

$$
\text { SGS Price }=F\left(P_{G i}\right)+f\left(\alpha^{*}\left(\text { Use allowed }-\sum_{1}^{k}(\text { Use })\right)\right)+f\left(\beta *\left(T_{\max }-T_{k}\right)\right)
$$

where $F\left(P_{G i}\right)=$ the base price function for the SGS resource $P_{G i}$

$f\left(\alpha^{*}\left(\right.\right.$ Use $\left.\left._{\text {allowed }}-\sum_{1}^{k}(U s e)\right)\right)=$ a price function based on the number of uses remaining of the SGS resource $P_{G i}$ out of a total number of uses $k$

$f\left(\beta^{*}\left(T_{\max }-T_{k}\right)\right)=$ a price function of time remaining between current time $T_{k}$ and $T_{\max }$ $T_{\max }=$ the future time constraint within which to dispatch $P_{G i}$

Equation 5-Time and demand dependent price function

The desired effect is to increase the price to dispatch a scarce SGS resource as it is used, but relative to its total remaining use, while also accounting for the time remaining to use the resource. However, in order to demonstrate the use of an increasing price function within this research, the following price function will be utilized in lieu of the above approach in order to simplify the model while still demonstrating SGS resource price dynamics:

$$
\text { Resource Price }=F\left(P_{G i}\right)+f\left(U s e_{j}\right)
$$

where $F\left(P_{G i}\right)=$ the base price of the resource $P_{G i}$

$f\left(U s e_{j}\right)=$ price increase for each subsequent use $j$ of the resource

Equation 6 - Demand dependent price function 
This price function acts simply to increase the price by the same amount for each time a SGS resource is scheduled. For example, if a resource is scheduled for dispatch, the first dispatch should cost less than the second and the second less than the third, and so forth.

\subsubsection{Demand response}

Demand response (DR), also called direct load control, refers to influencing the demand for energy at a customer site (e.g., turning off/on a water heater, changing a thermostat setting which affects HVAC, turning off/on "smart appliances," and so forth). There are two types of demand response: opt-in and automated DR. Opt-in DR relies solely on the customer to optionally reduce load after receiving a communication signal from an ESP. Of interest here is automated DR, which may be turned off or on by an ESP in response to grid conditions, such as peak loads or high prices within real-time power markets. Automated DR on average has been shown to account for a 40 percent decrease in peak energy usage among residential and commercial customers, at a cost that is approximately onethird of the cost of generation to cover the same loads [48]. Given such potential, automated DR is often considered a resource used for reliably reducing peak energy consumption among most ESP [48].

There are two types of costs to be considered when pricing demand response: the ESP cost and the customer cost. The following types of costs are common to ESP within demand response programs or the administration of those programs [48]: 
- direct rebates or incentives to customers;

- engineering, software systems, and support;

- administration and implementation;

- evaluation, measurement, and verification of load response; and

- marketing and customer education.

Customer costs may include money spent on technology upgrades, such as communications equipment, or DR compatible responsive devices at the premises, such as smart water heaters, thermostats, and so forth. These costs may be bundled to determine the price to dispatch the SGS resource or asset.

In order to model DR, consider Equation 1, where a generation resource $P_{G i}$ is a component of the power balance equality constraint to reliably match supply power with electrical load. Notably, an automated DR resource with a reliable response may take the form of $\left(-P_{D}\right)$ which simply reduces the total generation required, where $\left(-P_{D}\right)$ is the sum of the DR devices in the system responding to the signal to decrease load. Consider Equation 3 may be expanded to include DR:

$$
\operatorname{Min}\left[\sum_{i=\mathbf{1}}^{\boldsymbol{n}} \boldsymbol{F}\left(P_{G i}\right)+\sum_{j=\mathbf{1}}^{\boldsymbol{m}} \boldsymbol{F}\left(P_{D j}\right)\right]
$$

where $F\left(P_{D_{j}}\right)=$ the price function of the $\mathrm{j}^{\text {th }}$ available DR resource $F\left(P_{G i}\right)=$ the price function of the $\mathrm{i}^{\text {th }}$ available generation resource $n=$ number of available SGS generation resources $m=$ number of available SGS DR resources Equation 7 - Generation and demand response cost minimization function 
Notably, the price function component $\boldsymbol{F}\left(P_{D_{j}}\right)$ is determined by the ESP as a function of program price recovery or willingness to pay, or may be derived from actual purchases of DR if the DR resource is being purchased on the market from a DR aggregator.

In addition to the base price, DR like DSG may also be considered to have an increasing price component due to demand, duration and time-of-use restrictions, where each use of the resource detracts from future flexibility to meet balancing area load requirements, as in Equation 6. The time-of-use restrictions may come in many forms depending on the customer. For example, "a DR resource may be called for action anytime" or "a resource may be called between 5:00AM and 5:00PM, but never on Tuesdays, and not on the weekends between 7:00AM and 8:00AM" [37]. The research here will model DR as a generation resource agent, able to reduce load in the system. DR resources will also have time and price dependent characteristics as generation resources from Equations 4 and 6.

\subsubsection{Battery inverter systems}

Battery inverter systems (BIS) for the grid are one of the most recent innovations enabling a more efficient and reliable grid. Utility-scale energy storage systems (ESS) are not uncommon; previously such systems have been used as distributed power back-up technology within many customer premises (e.g., data centers, call centers, emergency operations centers, industry control centers, and the like). Several projects have recently demonstrated that utility-scale ESS may be employed to manage over-generation, integrate intermittent renewable generation 
like solar and wind, as well as enable microgrid islanding. BIS may also be engaged as reserves, to provide reactive power support services, and to maintain grid stability during an outage [49] [50] [51].

In the model here, a BIS resource may be scheduled to aid in load balancing or least-cost generation as any other generation type SGS resource. As such, there is a recognized need to optimize the discharge function of the BIS. However, unlike the BIS discharge function that is often requested during peak loads to avoid peaking charges or offset the addition of inefficient peaking generation plants with high costs, BIS charging most often occurs late at night when the lowest power prices are consistently found in the market. Given average market conditions throughout a year, arbitrage of the market is possible each cycle of day to night by consistently charging late at night and discharging during peak load hours. Assuming such market conditions are appropriate for consideration in the model approach here, the only BIS feature of interest will be the discharge schedule.

A discharge opportunity is subject to the minimization criteria in Equation 3 for the overall balancing area cost of operations. The BIS discharge price may be considered a function of both the charge rate and the cost of the energy supplied to charge it. One method to model the price of the BIS discharge is using the weighted average cost of all charges within the battery system [12]. This method is nearly identical to how natural gas is priced in storage facilities that accept and discharge gas at varying rates over time [24]. Consider Equation 8: 


$$
\boldsymbol{F}\left(P_{B I S}\right)=\alpha+\sum_{i}^{n}\left(C\left(P_{B I S}\right)_{i} *\left(K_{i}\right)\right)
$$

where $\boldsymbol{F}\left(P_{B I S}\right)=$ the cost of BIS generation

$\alpha=$ ESP adjustment (i.e. hedging or opportunity cost)

$C\left(P_{B I S}\right)_{i}=$ the price of power during the $\mathrm{i}^{\text {th }}$ charge to the BIS

$K_{i}=$ the percent of the BIS charged from the $\mathrm{i}^{\text {th }}$ charge as a percent of maximum charge

$n=$ number of charges

Equation 8 - Battery charge dependent price function

Notably, if a battery is discharged fully, then following a full charge, the price of the energy available in the battery for the next discharge is simply the total cost of the power from the previous charge session. However, if the price of the energy changes over time as the battery is charged, then the price function remains a weighted average. Thus, BIS may have a price function based on the percent of charge used, the supply price dynamics over time, and the total number of charge and discharge events.

Affecting the price of an energy storage asset is a BIS's physical condition, which may deteriorate over time due to chemical reactions between the electrolyte and the anode. Thus, BIS are strictly limited to a total number of uses. As BIS in [49] [50] were typically expected to last for ten years, this will not be considered in this research as a complex function, but simply demonstrated as a component of cost that is usage dependent, as in Equation 6. Here, the scarcity of a resource is modeled with an increase to the price of each use [43]. 
The minimization constraint from Equation 7 may be expanded to include optimization for discharging the BIS:

$$
\operatorname{Min}\left[\sum_{i=\mathbf{1}}^{n} \boldsymbol{F}\left(P_{G_{i}}\right)+\sum_{j=\mathbf{1}}^{\boldsymbol{m}} \boldsymbol{F}\left(P_{D j}\right)+\sum_{k=1}^{l} \boldsymbol{F}\left(P_{B I S_{k}}\right)\right]
$$

where $F\left(P_{G i}\right)=$ the price function of the $\mathrm{i}^{\text {th }}$ available generation resource

$F\left(P_{D j}\right)=$ the price function of the $\mathrm{j}^{\text {th }}$ available DR resource

$F\left(P_{B I S K}\right)=$ the price function of the $\mathrm{k}^{\text {th }}$ available BIS resource

$n=$ number of available SGS generation resources

$m=$ number of available SGS DR resources

$l=$ number of available BIS resources

Equation 9 - Cost minimization function

\subsection{Model computation time}

The introduction of regulated markets to operating North American power systems was a result of FERC's 888 and 889 landmark rulings from the late 1990s, which promote competitive wholesale electricity trading through a requirement for open access transmission services [52]. As a result, ESP in many of these markets buy and sell power on an hourly schedule, or in newer markets, within an hour (e.g., fifteen minute schedules). Market dispatch today is generally unconstrained in terms of computing time permitted. A typical hourly market, such as those used for hourly SCED, requires a solution within forty minutes from the beginning of the prompt hour [24], that is, a dispatch must be entered into the electronic market system prior to twenty minutes before the start of the scheduled hour. Newer 
fifteen-minute markets are more burdensome for the real-time operator, but realtime analysis tools are generally able to compute dispatch solutions in the time allowed [53]. However, the California Independent System Operator imbalance market requires a four second dispatch decision [54] in order to participate. Energy imbalance markets often require fast decisions to assist with congestion or to correct system area control error (ACE) issues affecting overall interconnect reliability. Emerging five-minute markets will also test the performance of computational tools used for dispatch analysis. With this in mind, it is desirable to develop tools that efficiently dispatch many SGS within, at most, only a few seconds.

\subsection{Transactive market systems}

Transactive systems (TS) were first conceptually demonstrated in 2007 within the Olympic Peninsula smart grid project undertaken by the U.S. Pacific Northwest National Laboratory [54], and later commercially demonstrated in the Pacific Northwest Smart Grid Demonstration project [50]. Participants in TS can include load serving entities such as ESP, generation providers, load response providers, transmission service providers, interconnect system operators (ISO), and regional transmission operators (RTO) [13].

To understand TS, first consider a market in which buyers and sellers "bid" or "ask," respectively, submitting prices to the market operator. Participants indicate desired purchases and sales of commodities based on their respective utility or cost functions and bid or ask accordingly; a central market clearing entity (i.e., a commodities exchange) may then analyze the bid and ask prices submitted, 
establish a clearing price among these values that will clear the highest number of trades for the available supply, and thus determine the settlement price. In an electricity transactive market system, buyers of electric power do not bid a price. Rather, they bid their expected demand for power at a location in the grid, in response to the advertised price schedule that is location specific, called the locational marginal price (LMP). LMP refers to a geographically constrained commodity that may be priced based on its scarcity of supply to a particular location. Generation sites supply their respective prices for generation expected to serve load into a transactive market clearing coordinator, based on their forward prices for fuel, expected environmental conditions, and so forth.

The transactive market coordinator then clears the market in order of leastcost dispatch, matching generation to expected load for the available transmission paths, once every five minutes. Notably, both the load and the price schedule exchanged in the TS report on future periods for a limited time horizon, that is, composing (1) a real-time dispatch price and a future expected price for delivered energy; and (2) a real-time demand and a forecasted schedule of demand for transmission interconnect supplied power. Each ESP has provided their scheduled demand in response to the advertised price for transmission supplied power at each grid interconnect location.

The price signal is called a transactive incentive signal (TIS), and the load signal is called a transactive feedback signal (TFS). Every five minutes, based on TFS responses from these TS participants, the future TIS may be adjusted through the 
use of an algorithm accounting for each market participants' expected load including the constraints of the transmission system; where congestion management is required due to limited available transmission capacity, the TIS may be increased, locally, only to those entities which may then impact congestion should their demand decrease. Likewise, where congestion is absent, or more flow in the system is desired, the TIS may be relaxed. Thus, TS also act as local marginal price management systems among grid stakeholders, which anticipate and effectively coordinate least-cost economic dispatch while minimizing transmission congestion [12] [55]. In [56], TS have been demonstrated to control distributed generation, balancing with renewable generation, demand, storage, and congestion in the power system through the use of these TIS and TFS signals.

\subsubsection{Transactive system approach}

The August 2004 multibillion dollar outage debacle in New England-blamed on a tree-speaks to the importance of preventing electrical grid faults, which annually cost ratepayers, utilities, and the government between $\$ 30$ billion (USD) to $\$ 130$ billion [57]. ESP thus have systems to automatically isolate sections of a distribution or transmission network, intended to shield the overall larger grid from such harmful events.

Transactive grid locations, also called nodes, enable another type of isolation, in which a virtual segment of an electrical network is isolated economically within the larger inter-utility grid interconnect or regional distribution network. The node is actually a software artifact, and is assigned a group of local SGS resources such as 
DR, BIS, and DSG. The node manages the assigned resources (i.e., their dispatch and forecasted schedules of use) depending on the TIS price and SGS availability.

The momentum to build many such interconnected distributed systems is growing. Jon Wellinghoff, former Chairman of FERC, recently quipped that "the whole model of the utility as a vertically integrated entity will break down completely"-pertaining to utilities being pressured to implement distributed control systems [58]. Clearly, if isolated physically from the transmission system, the price of locally supplied energy is limited to the price of the responsive SGS resources dispatched to meet (or decrease) the load. Considering a grid of this physical nature, the power system equality function in Equation 1 may be restated to include transmission grid power supply availability, here called $P_{T}$, which can be modeled as any other generation source, as follows:

$$
\left.\left.P_{D}=\left(\sum_{i=\mathbf{1}}^{n}\left(P_{G i}-P_{D i}\right)\right)-P_{L}\right)+\left(\sum_{j=\mathbf{1}}^{m} P_{T j}\right)-P_{L T}\right)
$$

where $P_{D}=$ Power demanded at time $t$ within the transactive grid area under control $P_{G i}=$ Power generated by the $\mathrm{i}^{\text {th }}$ available transactive generation resource $P_{D i}=$ demand reduction by the $\mathrm{i}^{\text {th }}$ available transactive DR resource $P_{L}=$ loss determinant for the local grid for power supplied by SGS resources $P_{T j}=$ power provided from the transmission tie by the $\mathrm{j}^{\text {th }}$ interconnect resource $P_{L T}=$ loss determinant for the power supplied by interconnect resources Equation 10 - Transactive balancing constraint function 
Thus, in a transactive system, each generation source that is a transmission connected source may be included as an expansion to the term $P_{G i}$ and modeled as any other local generation source with a cost. Here, it is important that the model be able to remove resources with respect to time based on the price: in terms of the difference between the transmission supplied energy price and the SGS resource price where the difference is positive, then the SGS resource is scheduled; if the difference is negative, then the SGS resource remains unscheduled, resulting in the most efficient outcome so long as the price reflects the actual cost. 


\section{Model development}

Modeling is a method of solving problems. It concerns the process of abstraction: drawing the salient features of a system from examples and data in the real world into the model, such that the model is a representative example of the system. Simulation builds on modeling, as a set of rules by which a model may change over time, given some initial state [59]. Notably, this research does not use simulation time to represent real-world time; instead, real-world time (the schedule forecasting horizon) is represented within the model all at once, and simulation time is used only to allow a series of communication steps to occur between agents, as well as agents and the environment, in order to formulate model results.

\subsection{ABM and complex systems}

Simply put, computer programs may be developed to mimic aspects of the behavior of entities within a real-world system, and the programs may be allowed to interact in a virtual environment for the purposes of researching the system [60]. In this way, ABM has demonstrated compelling realistic simulations of "real" behavior, including flocking, cooperation, sensing, and many other emergent system phenomena; due to its unique modeling approach, ABM has been called "a third way of doing science besides deductive and inductive reasoning" [61]. One noteworthy aspect of ABM is the ability to "grow a model" from the ground-up [62]. This refers to allowing a simulation to develop real-world like behavior by modeling individual behavior of system actors or components, and as such, to reveal more complex 
relationships that occur as agents interact with each other and the environment. This is relevant to this research because of the "generative" nature of the smart grid and the following five characteristics that arguably lend themselves to modeling SGS with agents:

1. ESP depend on individual behavior of the customers to make their decisions about dispatch in real time;

2. Generation resources supplied in a market are isolated from the behavior of other plants, insomuch as they do not work together to decide which plant is to run at a certain time;

3. Plants may bid their price to supply energy to a central market for dispatch consideration, require that they run (such as nuclear plants which may pay ESP to take power rather than shut down for economic purposes), or fail to run for maintenance reasons;

4. A SGS may have its own custom constraints for system operation within each ESP transactive grid node (e.g., time-of-use or maintenance constraints), yet each must still meet operating rules regarding overall grid balance and respond to governance constraints that may influence the use of the SGS resource over time; and

5. Each SGS resource may be considered a competitor in larger trading realtime or day-ahead markets for regional power operations, where net marginal cost of supply drives an ESP's timely actions with resource commitments. Thus, an ESP power marketing operations team considers: 
(a) the ability to participate in the market optimally; and (b) balancing the system electrically. These are the fundamental aspects of long-term success and short-term strategic importance, respectively.

Due to these grid characteristics, the electrical grid containing SGS may also be considered a complex adaptive system. A complex adaptive system is defined as:

- consisting of a network of interacting agents, and exhibiting a dynamic aggregate behavior that emerges from the individual activities of the agents; and

- has aggregate behavior that can be described without a detailed knowledge of the behavior of the individual agents, and the actions of the agents in their environment can be assigned a value, such as performance, payoff, or fitness [63].

Thus defined, considering a network of SGS resources and their aggregate behavior in a transactive grid, the system is well described as a complex adaptive system, and as such, may be well modeled using an ABM approach. ABM's effectiveness for modeling complex systems is generally based upon the following [61] [62]:

- ABM may account for cost, social, environmental, and other decision factors;

- the ABM environment may have its own global variables and interact with agents;

- ABM simulates population heterogeneity through decision-making processes specific to "breeds" of agents in the model population; and

- ABM can illustrate emergence and other complex adaptive system behavior. 
In order to model the system of interest as an ABM, certain characteristics are important to include, namely, having specific reasoning, memory, and control aspects for the agents, as well as an ability to react to differing conditions in the environment. Agents will "reason" using the mathematical constraints as described in detail throughout Section 2, further discussed along with control aspects and the environment within Section 3.2.

\subsection{Developing the model}

Some agent-based simulation environments, such as the popular NETLOGO system, use a computing platform environment to accomplish their modeling that is adept for watching agent interactions as they unfold during the simulation, an approach that is feasible here. However, from personal experience, these types of agent-based models can sometimes be "slow" due to the amount of information that is traded between agents during run-time, the number of agents being managed in the software, and the capabilities of the hardware and software platforms to manage processing and graphics. The same may be said of many econometric approaches to dispatch problems: the amount of information to process and govern in a model impacts computational intensity and thus time to complete. When using a simulation as a solution search engine such as in this research, the processing time is especially relevant. Importantly, my approach here specifically limits the information traded between agents across different time periods, but in allowing such an exchange, permits the model to perform dispatch analytics for all forecasted time periods at once. 
Economic dispatch computing is a growing concern for many ESP real-time operations practices as the grid is integrated with many more complex responsive resources [53]. As real-time markets decrease their scheduling horizon from hours to minutes, the capability of dispatch and scheduling software platforms will be challenged. Many existing mixed integer linear programming tools (seemingly the most popular commercial tool for dispatch analysis) that analyze such systems today may take from a few minutes to several hours to produce a solution, depending on the complexity of the resource portfolio [24]. Here, I propose a dispatch model that is, at the very least, capable of performing in less than five minutes, as some markets are currently exploring [11], but preferably can perform in less than four seconds as in [54]. For this reason, this ABM has been developed as a software program that executes in a MS Visual Basic module linked to a SQL database. This approach draws heavily from concepts successfully demonstrated in [11], which show that using SCADA-connected database-driven controllers may achieve near real-time integration (sub-seconds to seconds) with server-based simulation assets, very much like the methods of using programmable logic controllers (PLC) and programmable automation controllers (PAC) in distribution engineering control applications. This will be discussed in detail in Section 3.3.

\subsubsection{Environment}

One fundamental aspect of $\mathrm{ABM}$ is that agents may interact with the environment [59]. In many agent-based models, the environment is composed of "patches" that correspond to physical locations. It is these patches that create a 
framework for an agent to interact with an environment location or other agents, typically as a consequence of their location to one another. Agents' opportunities to interact being relative to their location in the environment are used to define relationships through time. Every interval, or environment patch, contains two time-variant variables: (a) the TIS price, at that specific time interval, and (b) the expected load $P_{D}$ in the grid, at that interval. Thus, the environment in the model here is chronological time rather than location, starting with the present located at the origin, and forward into the future traveling along the $\mathrm{x}$-axis. Pertaining to Equation 1, load $\left(P_{D}\right)$ is setup hourly in the model and preloaded into a database table "Load" for fifty time intervals. A TIS price forecast also contains fifty hourly time intervals and is preloaded into a database table "Price." Notably, both load and price could be loaded from an external source, such as a real-time market system communication link, or a load forecast model. An example of TIS market data is shown in Figure 3.1.

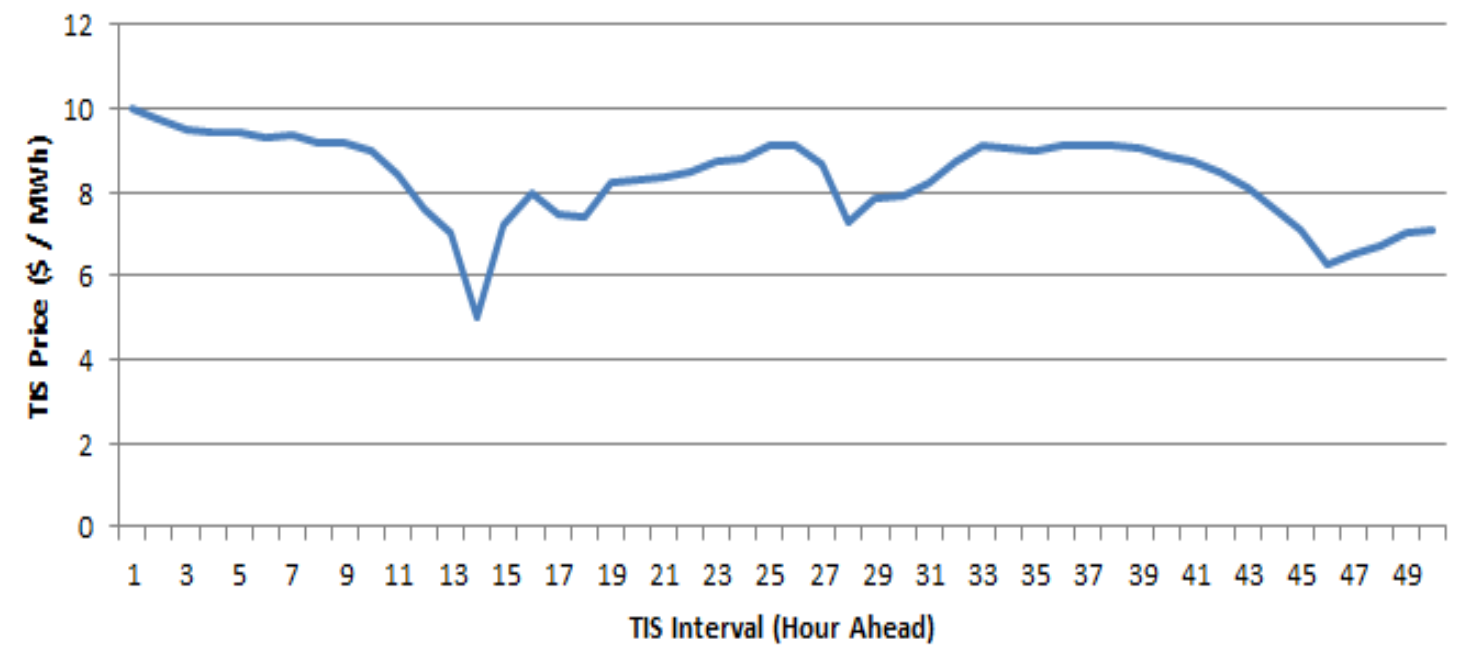

Figure 3.1 - Environment variable: TIS price 


\subsubsection{Agents}

Agents represent the SGS assets in the system, namely a distributed generation (DG) resource, a DR resource, and an energy storage system (ESS) resource. Most important, one agent of each resource type (e.g. DG, ESS, DR) is assigned to each time interval in the environment. This is realized programmatically using arrays to store each agent's memory logically for each interval in time. Each agent's initial attributes are stored in a table for agent use, an example of which is shown in Figure 3.2.

\begin{tabular}{|c|c|c|c|c|}
\hline Asset & - assetName - & Cost & load - & costIncreasePerUse \\
\hline & $1 \mathrm{SGSDR}$ & $\$ 50.00$ & 100 & \\
\hline & 2 SGS DG & $\$ 50.00$ & 800 & \\
\hline & 3 SGS ESS & $\$ 30.00$ & 200 & \\
\hline
\end{tabular}

Figure 3.2 - Agent asset table

In Figure 3.2 the "Asset" (columnar data) refers to the index value of the agent in the table, and is used for referential integrity for relationships in the system. "AssetName" refers to an agent type, also called a breed in agent-based simulation jargon. "Cost" refers to the initial assigned dispatch price for each SGS agent in \$/MWh, while "costIncreasePerUse" refers to the increase in asset dispatch price applied for each subsequent resource use within a scheduling period, pertaining to Equation 6. "Load" refers to the contribution to load from a generation resource when operating without consideration for ramp times, pertaining to Equation 10 and satisfying the upper bound for Equation 4. 
Agent memory is accomplished using arrays. A looped process is undertaken to assign each environment constraint to each agent's memory—load and TIS price-specific to each time interval.

Agent memory also stores:

- each agent's cost difference with transmission price specific to each time interval, accounting for price increases from use, allowing power balance pertaining to Equation 10;

- each agent's dispatch rank, in order of least to highest cost, among agents within their assigned time interval, pertaining to the least-cost (minimization) dispatch criteria in Equations 3, 7, and 9;

- each agent's individual load contribution;

- the cumulative load contribution of agents as dispatched by rank, (i.e., the amount of load remaining to serve in the grid) pertaining to the constraint in Equation 10 while satisfying Equation 4; and

- each agent's dispatch decision for each interval (scheduled or not scheduled).

\subsection{Model approach}

It is helpful to understand the model operation by reviewing a graphical representation of the environment populated by agents, shown in Figure 3.3. 


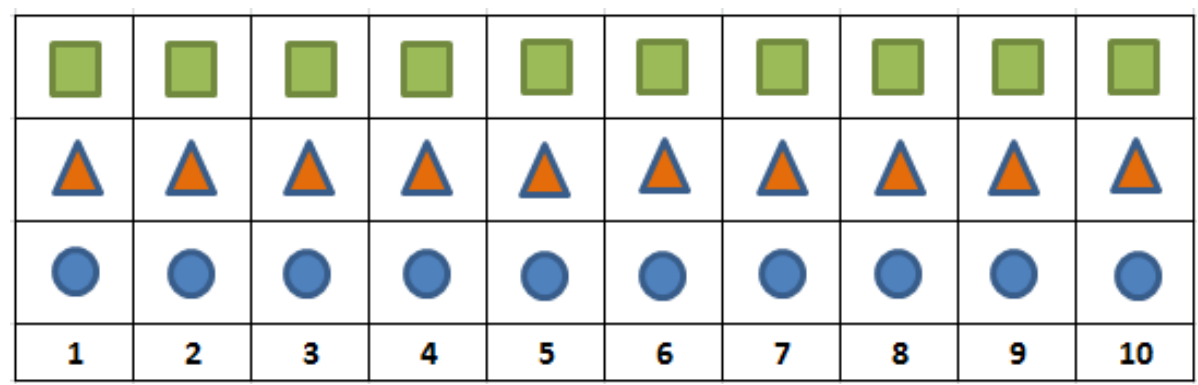

Figure 3.3 - Graphical model representation

Figure 3.3 shows a sample environment with forecast interval times numbered 1 through 10, or one hour pending dispatch and nine hours of forecasted schedule. Shown are three SGS resources- a square, a triangle and a circle- one of each that resides in every time interval, and thirty agents total. Agents within a time period refer to each other agent in that interval to determine their rank in dispatch- based on price and availability—as agents across time intervals may exchange information only with their own breed to determine the best possible interval of opportunity. In this way, total information transfer between agents in the model is strictly limited. For example, a triangle agent in interval 1 may exchange data about its dispatch rank with the circle and square agent inside interval one, as well as with all other triangle agents across time to the model's forecast horizon limit.

Programmatically, the system uses a series of five steps that correspond to agent actions, using simple rules, which result in agent behavior that quickly identifies the transactive dispatch and forecasted schedule:

1) A transactive clearing price for each specific interval is loaded to each agent's memory, transferred from the environment; 
2) In each interval, each agent subtracts their own price from the environment price; the difference, if positive, means the agent dispatch is potentially optimal for that interval among all possible dispatches of that agent breed, also called "in the money" within financial trading jargon. If the difference is negative, then the agent may not dispatch in that period, since transmission-supplied power is least-cost. The result is stored to each agent's memory. An example of the agent marginal cost calculation across five intervals is shown in Figure 3.4.

\begin{tabular}{|c|c|c|c|c|c|c|}
\hline & $\begin{array}{r}\text { Transactive } \\
\text { Price (TIS) }\end{array}$ & 10 & 5 & 3 & 7 & 2 \\
\hline \multirow{2}{*}{$\begin{array}{l}\text { Agent } \\
\text { Cost }\end{array}$} & $\begin{array}{l}\text { Interval } \\
\rightarrow\end{array}$ & 1 & 2 & 3 & 4 & 5 \\
\hline & Agent \# & \multicolumn{5}{|c|}{ Agent Memory } \\
\hline 4 & 1 & $10-4=6$ & $5-4=1$ & $3-4=-1$ & $7-4=3$ & $2-4=-2$ \\
\hline 6 & 2 & $10-6=4$ & $5-6=-1$ & $3-6=-3$ & $7-6=1$ & $2-6=-4$ \\
\hline 8 & 3 & $10-8=2$ & $5-8=-3$ & $3-8=-5$ & $7-8=1$ & $2-8=-6$ \\
\hline
\end{tabular}

Figure 3.4 - Agent behavior: Calculation of economic dispatch potential

3) Each agent that is assigned to potential dispatch compares their dispatch cost difference, and depending on interaction with other agentsfirst across intervals within their breed, and then within the same interval against other resource agents — they assign themselves a 2-dimensional rank. An example is shown in Figure 3.5. In this example, within the first transactive interval "Int 1", Agent 1 calculates a difference of 6 with the transmission environment price, which when compared to other opportunities for Agent 1 in the future (across other intervals), and is found 
as the most optimal. In addition, compared to other opportunities to reduce load in the same interval (among other resource agents), it was also the greatest difference, thus the least-cost opportunity.

\begin{tabular}{|c|c|c|c|c|c|}
\hline $\begin{array}{l}\text { Rank } \\
\rightarrow\end{array}$ & 1 & 2 & 3 & 4 & 5 \\
\hline $\begin{array}{l}\text { Agent } \\
\#\end{array}$ & \multicolumn{5}{|c|}{ Agent Memory } \\
\hline 1 & Int 1 ( Price $\Delta=6$ ) & Int 4 ( Price $\Delta=3$ ) & Int 2 ( Price $\Delta=1)$ & 0 & 0 \\
\hline 2 & Int 1 ( Price $\Delta=4)$ & Int 4 ( Price $\Delta=1$ ) & 0 & 0 & 0 \\
\hline 3 & Int 1 ( Price $\Delta=2$ ) & 0 & 0 & 0 & 0 \\
\hline
\end{tabular}

Figure 3.5 - Agent behavior: Calculation of rank for dispatch

In summary, Agent 1 had the best opportunity in interval 1, with a cost difference of 6; the second best dispatch for Agent 1 was calculated within interval 4, and the third best in interval 2. Agent 2 had the second best opportunity in interval 1 with a cost difference of 4 , and so forth.

4) Each agent's memory stores the dispatch rank by interval. As each dispatch of an agent is discovered, the Agent's price is increased and stored in the Agent's memory as the new price.

5) Each agent dispatched may reduce the load —in the order of dispatch — subtracting from the grid load environment variable until the power balance is met, pertaining to Equation 10. The load following function for the last dispatched resource is assumed as a control outcome of the model results (i.e., it is considered a distribution control function not a power marketing dispatch business system function). Additional agents may not dispatch once the load has been met, meeting the constraints in Equation 10. 
The resulting dispatch is maintained in agent memory. The ideal model output results in the most efficient dispatch for the SGS agents through time.

\subsection{Model interface}

A user-interface was developed containing an asset management interface, the optimization dispatch tool, and a report builder to facilitate model testing. The interface dashboard is shown in Figure 3.6.

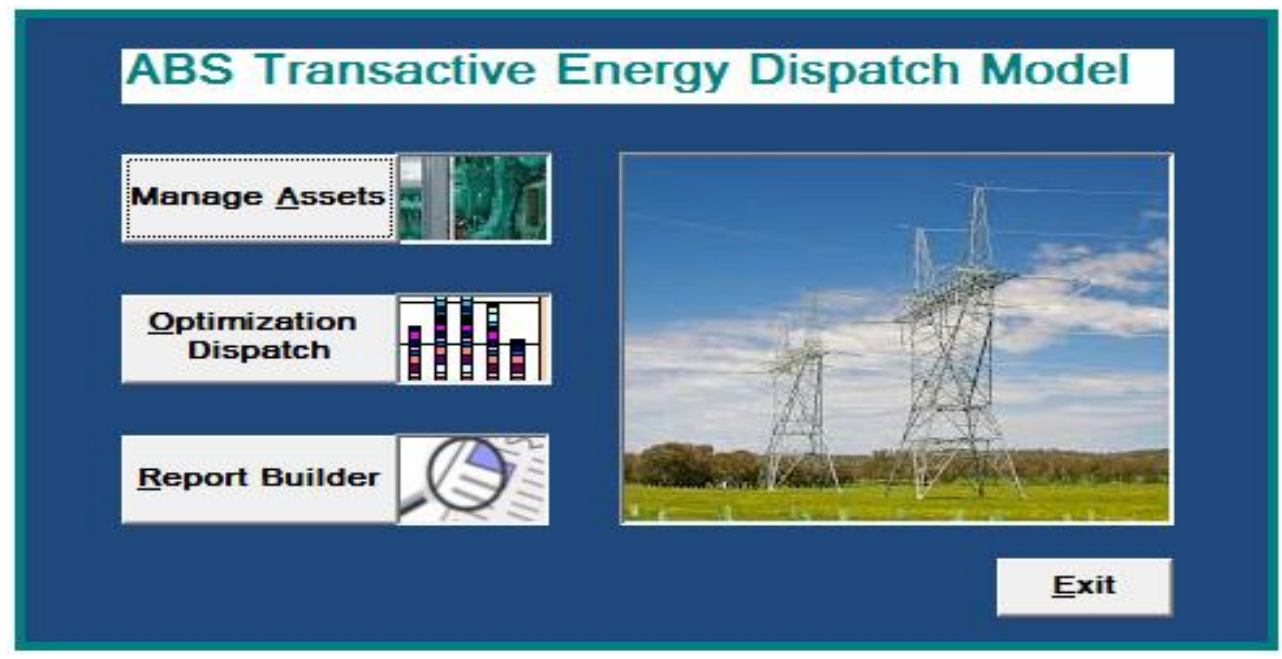

Figure 3.6 - Simulation interface 


\section{Model testing}

\subsection{Model verification}

Model verification concerns a series of tests to make sure a model is designed correctly. Verification occurred in three stages: first, the system was debugged with respect to the code within the database system. Second, the code was notated and, using step through analysis, was manually checked for errors. Finally, value registers were written into the code to monitor values during run-time, and array value outputs were checked to ensure that values from the data tables were used throughout the system correctly. Each step was successful and revealed no technical issues using the final draft of the code. Once debugged, final model verification was accomplished step-by-step using the example described in detail in Section 3.3, including the model verification data confirming the calculations found in Figures 3.4 and 3.5.

\subsection{Model validation}

Model validation concerns producing evidence you have designed the right model (i.e., generating meaningful model results). This thesis involves producing results that are measurable; model output is compared to real-world expected outcomes to convince stakeholders that the output is satisfactory. This is accomplished from a perspective that is appropriate to the level of model fidelity and gauges the usefulness of the model with respect to the specific research question set out in Section 1.4. 


\subsubsection{Validation approach}

A series of validation scenarios were logically chosen in order to represent an increasing level of difficulty in terms of dispatch and scheduling behavior, and to ensure the results are aligned with the need for the model as defined in Section 1.4. Moreover, in responding to each scenario successfully, the model results build up increasing evidence that is used to gauge the success of the model design and build confidence in the modeling approach. The model needs to perform efficient transactive dispatch and scheduling tasks given the following market system characteristics:

1. Supply price, or TIS dynamics, including (a) slow moving or fast moving TIS (i.e., degree of price change over time is addressed) with respect to ESP SGS asset price characteristics over time; (b) frequency of TIS events or price spikes (i.e., single and multiple opportunities to dispatch are addressed); and (c) length of price events (i.e., how long a TIS event or price spike lasts);

2. SGS resources with prices either well below, near, or above the TIS, resulting in a dynamic dispatch potential state over time;

3. Dynamic prices of SGS resources, in terms of price function rates of change (i.e., accelerated price change or a slow change compared to the change in the TIS price); and

4. Dynamic power balance constraints over time (i.e., changing loads). 
Various aspects of each scenario are drawn from each of these characteristics in Section 4.2.2, resulting in tests of varying complexity.

\subsubsection{Validation scenarios}

Scenario 1 tests the ability of the model to respond to the least complicated transactive market TIS, with a steady TIS price across all scheduling intervals well below the dispatch price of any individual SGS asset. The expected model response contains a dispatch only using transmission-supplied power.

Scenario 2 tests the model response to a single TIS event. A TIS event is a price spike above any SGS resource price, indicating it is more efficient to use the resource rather than real-time market derived commitments. Scenario 2 builds on answering the research question by characterizing model response where the SGS portfolio contains multiple SGS resources which could respond. In this scenario, a significant TIS spike is set for a single future interval. One SGS asset is set with a price at the margin of the TIS while other resources are constrained by price (i.e., much higher prices to dispatch than the TIS price event maximum price). The expected model response should contain a schedule with a single SGS asset to dispatch during the interval of the TIS price event.

Scenario 3 tests the model for response to TIS price change, dynamic SGS price, and TIS event duration. Scenario 3 adds to answering the research question by characterizing model response to a fast-acting feed-forward demand-dependent price function (i.e., increasing the price of an SGS asset quickly over time in relation 
to the TIS price). Thus, the SGS asset's price function variable is set to rapidly increase after a single dispatch, surpassing the TIS price increase in the next subsequent forecasted dispatch period. This tests the model's ability to respond to a market where a price spike occurs across multiple future intervals, but where a managed asset may be priced to only dispatch once within the scheduling horizon given a TIS price event. For example, DR and BIS SGS tend to dispatch only once per day [37]. The demand-dependent price function takes the form of Equation 6. The expected model response is to schedule a single dispatch of the SGS asset during the price event despite multiple intervals of a TIS price increase.

Scenario 4 further tests the model for response to TIS price change and SGS availability, but with a long TIS event duration. This scenario adds to answering the research question by demonstrating the model's response to a slow-acting feedforward demand-dependent price function. The SGS asset price variable is set to moderately increase after each dispatch, but such that it does not immediately surpass the TIS price increase rate for several TIS intervals. Conceptually this represents transactive market behavior where TIS price may increase for longer periods of time within the forecasting horizon rather than a single sharp spike. The expected model response is similar to scenario 3 , but should contain multiple dispatches of the SGS asset throughout the TIS price spike, until the asset price increase- acting over multiple dispatches- pushes the SGS asset price above the TIS price. 
Scenario 5 tests the model for response to TIS price change, a short TIS price event duration, as well as with multiple available SGS assets. This scenario adds to answering the research question by demonstrating the model's capability to manage multiple available assets, where each asset is priced below the TIS for some intervals. In this scenario, the SGS assets are all assigned the same initial price within the schedule horizon. This scenario characterizes a market where a significant TIS price spike may occur in a single future interval within the scheduling horizon, and where dispatches of multiple SGS assets are permitted due to the elevated TIS price. The expected model response will demonstrate dispatches of each SGS resource during the same interval as the price spike event.

Scenario 6 tests the model's response to fast TIS price changes with respect to the SGS asset price, similar to scenario 5. It contains a single TIS price event with a short duration, and considers multiple SGS assets as available over time. It builds on the complexity of model validation by assigning each asset a different initial dispatch price. This scenario adds to answering the research question by demonstrating the model's capability to dispatch under market conditions where a significant TIS price spike occurs in a single future interval within the scheduling horizon, and where dispatches of multiple SGS resources are permitted due to the elevated TIS price over time, but not every SGS is expected to dispatch due to the difference between the TIS price and the SGS dispatch price. The expected model response should demonstrate dispatches of each SGS asset during the same interval 
as the short term price spike event, but only the SGS assets that were priced below the TIS price.

Scenario 7 is similar to scenario 6 in testing the model for its response to TIS price changes, but builds on model validation by adding multiple TIS price events. Multiple SGS resources are available, and each SGS resource is assigned a different initial dispatch price. This scenario adds to answering the research question by demonstrating the model's capability to schedule multiple SGS resources when considering multiple opportunities, and where TIS price rises slowly compared to the SGS resource demand dependent price function. The expected model response is to dispatch in an on/off pattern: schedule SGS resources to turn on as the TIS price passes each SGS resource dispatch price, off as the demand dependent price function pushes each resource dispatch price above the TIS price, then on again as the TIS price increases, and so forth.

Scenario 8 completes model validation testing. It builds on validation scenario 7 by adding a transactive node load constraint, such that all SGS assets are available for dispatch across multiple opportunities in time, but with limited grid loads pertaining to Equation 1 (i.e., power must be balanced with load and overgeneration from an additional SGS asset is not permitted). Thus, scenario 8 most closely resembles a "real market" containing all the dynamics expected in such a system, namely the features described in Section 4.2.1. A reference for every validation scenario in terms of transactive market system features is summarized in the Appendix. 
The expected model response for scenario 8 is a limited dispatch of SGS assets, dispatched in order of their price compared to the TIS, without dispatching additional assets beyond the first asset to exceed the grid load such that the asset may perform load following, as discussed in Sections 2.1.3 and 3.3. The increasing complexity of each scenario may be followed logically in Section 4.2 .3 for aiding in model validation.

\subsubsection{Testing results and analysis}

Validation scenario 1 tests for a transmission-only dispatch-with no available economic opportunity for any SGS assets to be considered in the schedule forecast due to their price. In this scenario and all others, in order to schedule a dispatch an agent must first satisfy the following constraint:

$$
\boldsymbol{F}\left(P_{T}\right)-\boldsymbol{F}\left(P_{S G S}\right)>0
$$

where $F\left(P_{T}\right)=$ the TIS price for transmission supplied power

$F\left(P_{S G S}\right)=$ the generation supply price of an SGS agent

Equation 11 - Agent price dispatch constraint 
In scenario 1 , the TIS price $\boldsymbol{F}\left(P_{T}\right)$ is set at $\$ 5.00 / \mathrm{MWh}$, with dispatch prices for each SGS agent set at $\$ 30.00 / \mathrm{MWh}$ for every interval. The model output resulting from scenario 1 is shown in Figure 4.1.

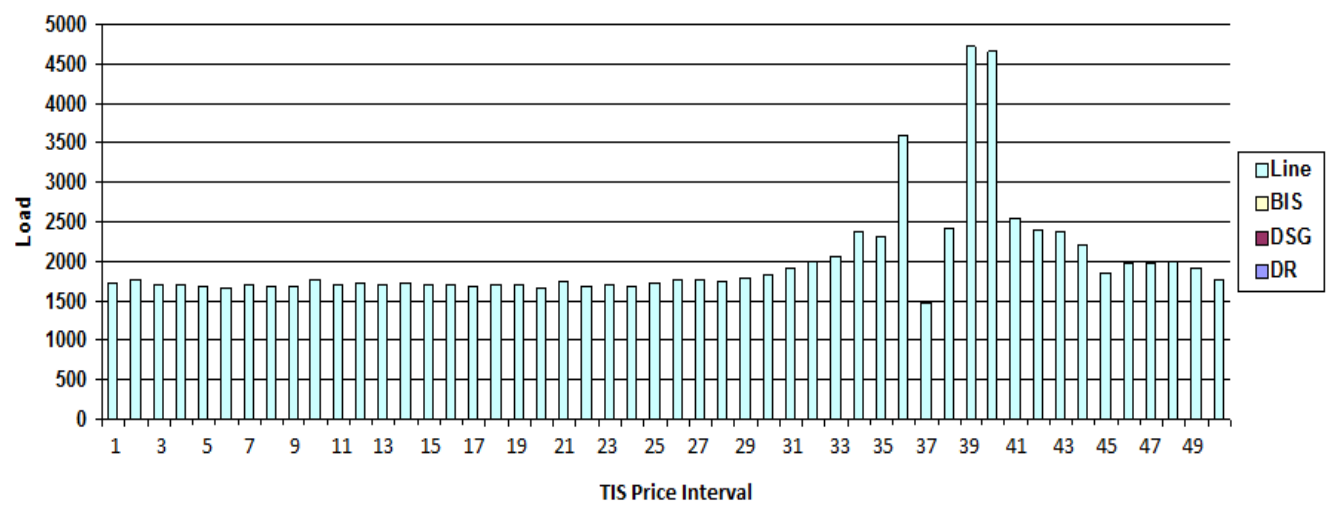

Figure 4.1 - Validation scenario 1: Model results

The bar graph shown in Figure 4.1 plots the load (y-axis) over time, and maps any scheduled SGS supply (an asset) as a percent of the load for each interval. In scenario 1, as no SGS assets were dispatched, the resulting model schedule shows that the transmission line resource (named "Line" in the legend, shown in light blue) is scheduled to satisfy the loads for every schedule interval. Thus, the output exhibits the expected economic dispatch behavior, such that transmission supplied power (at the TIS price) was scheduled over the entire forecast planning horizon.

Scenario 2 involves dispatch with one available SGS resource. In this test, all but one SGS asset is set far above the value of the TIS price event. As mentioned previously, this is intentional, in that from an architecture perspective two control functions are managed for the SGS asset using a single piece of information for the 
agent - the price of the asset—rather than sending both an availability indicator and a price for the agent to manage.

In validation scenario 2 , the TIS price $\boldsymbol{F}\left(P_{T}\right)$ is set to spike in interval 40 . The model settings and corresponding dispatch schedule are shown in Figure 4.2. In the settings, note the SGS resource price $\boldsymbol{F}\left(P_{T}\right)$ is set just below the transactive price event in interval 40. Thus, the expected model output should result in an agent dispatch at interval 40 from the single available SGS asset.

Scenario 2 model behavior results in the expected schedule, where the SGS agent dispatches during the TIS event interval. Other agents do not dispatch, as their prices are above $\boldsymbol{F}\left(P_{T}\right)$ pertaining to the constraints in Equation 11.

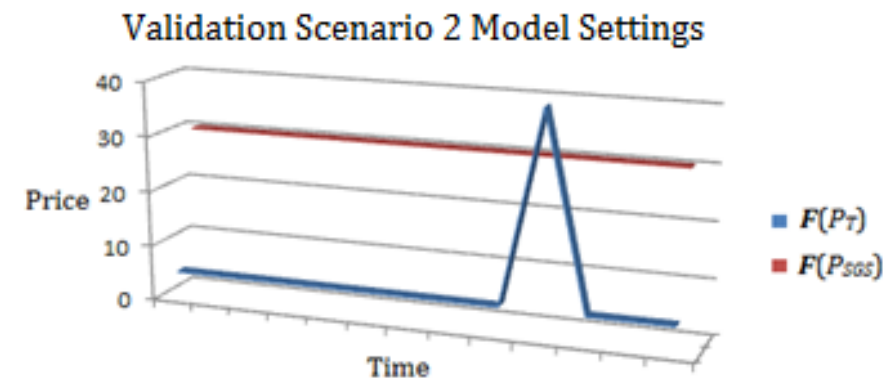

Scenario 2 - Model Schedule Results

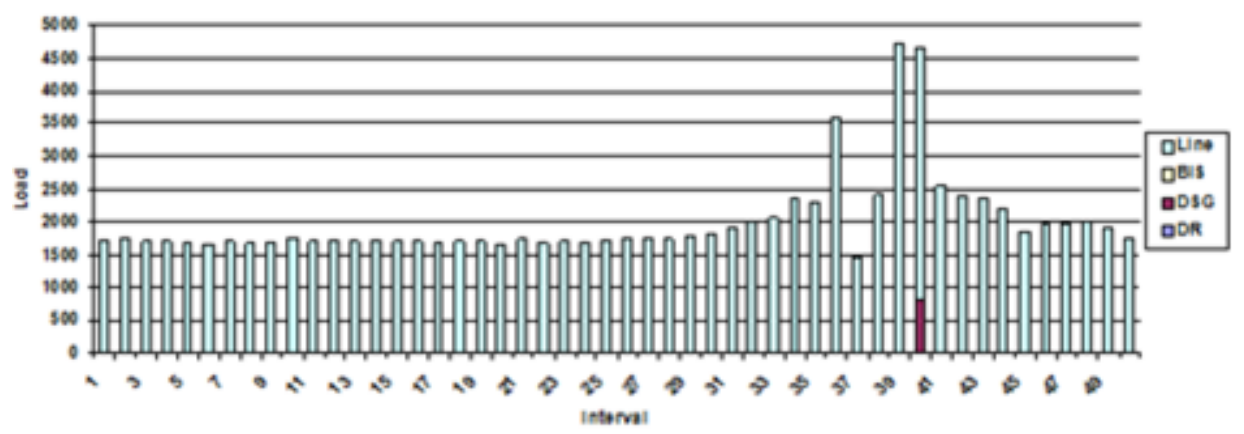

Figure 4.2 - Validation scenario 2: Model settings and results 
Validation scenario 3 investigates dispatch with one available SGS asset at the transactive price margin. In this test, each of the fifty SGS agents are priced just below the dispatch margin where $\boldsymbol{F}\left(P_{T}\right)=\boldsymbol{F}\left(P_{S G S}\right)$, so a scarcity price increase should make the resource inefficient following a single dispatch, and the model should not schedule a second dispatch.

Validation scenario 3 model TIS price curve and the corresponding model dispatch schedule are shown in Figure 4.3. The TIS price is set to spike in interval

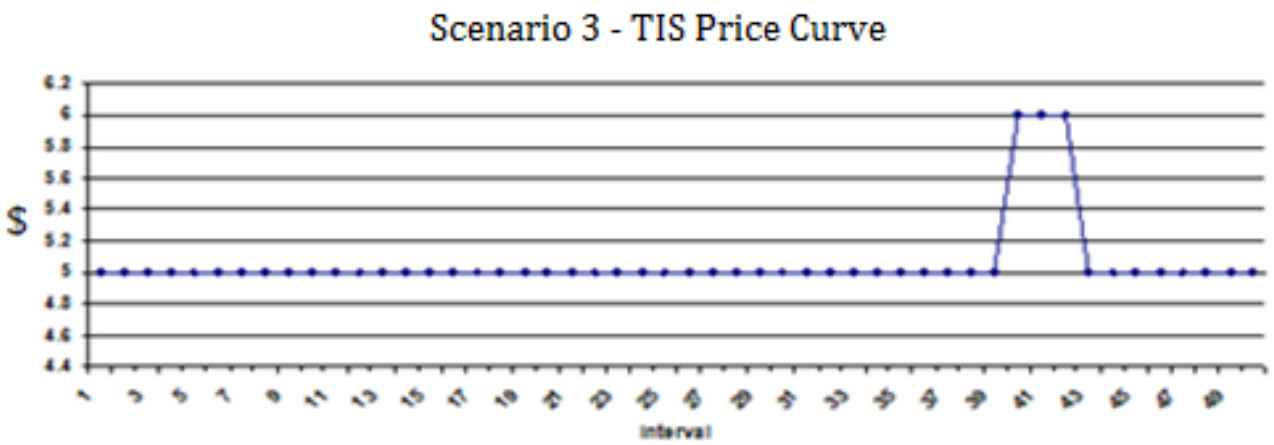

Scenario 3 - Model Schedule Results

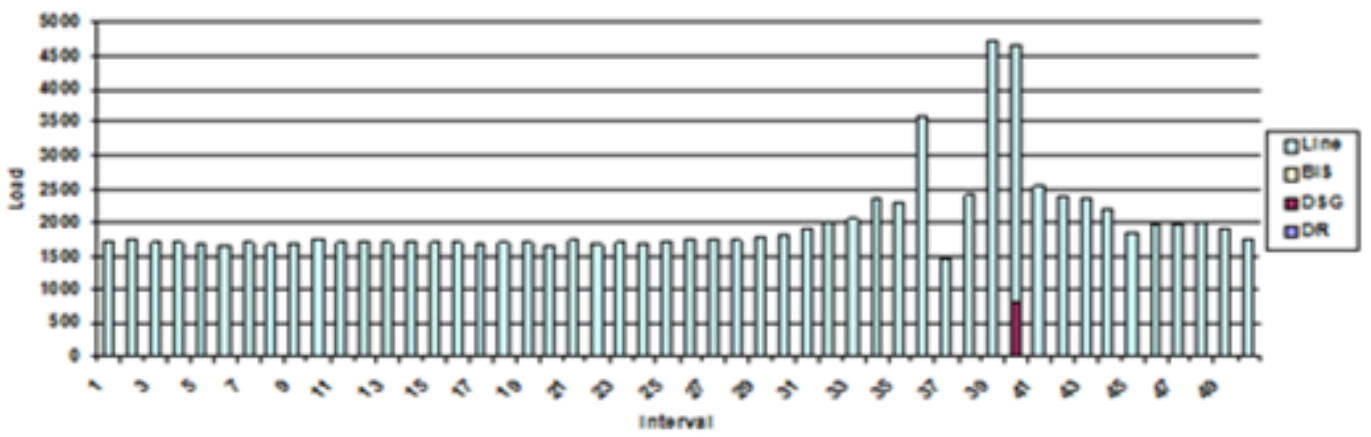

Figure 4.3 - Validation scenario 3: TIS price and model results

40, 41, and 42, lasting three intervals. Model output demonstrates the expected model behavior, such that transmission supplied power is utilized for the dispatch 
over the entire schedule horizon with exception to the one interval (in interval 40) where $\boldsymbol{F}\left(P_{T}\right)$ was priced above the SGS asset dispatch price $\boldsymbol{F}\left(P_{S G S}\right)$. Following the dispatch, the next agent (in interval 41) correctly increased its price function, thus removing the agent from the schedule in periods 41 and 42 , again producing the correct model behavior. This exemplifies transactive market behavior where the rate of change of the SGS price function exceeds the rate of change of the market price, resulting in only a single dispatch of the SGS asset.

Validation scenario 4 demonstrates scheduling with one available SGS asset priced just below the TIS price. However, the SGS resource price rate of change is less than the TIS price rate of change with a delta of $\$ 1.00 / \mathrm{MWh}$ vs. $\$ 3.00 / \mathrm{MWh}$, respectively. The model should schedule the SGS asset for dispatch within the first interval where the environment price $\boldsymbol{F}\left(P_{T}\right)$ exceeds the price of the agent $\boldsymbol{F}\left(P_{S G S}\right)$. Moreover, the resource should be scheduled for every interval following the first dispatch until the SGS resource price exceeds the transactive price (i.e., a different least-cost schedule solution is discovered using transmission supply resources). The SGS DSG agent's initial price and price increase per use, and the TIS price table excerpt specific to the TIS event for scenario 4 are shown in Figure 4.4.

\begin{tabular}{|c|c|c|c|c|c|c|c|c|c|}
\hline \multirow{2}{*}{$\begin{array}{l}\text { Agent } \\
\text { SGS DSG }\end{array}$} & & & \multicolumn{2}{|c|}{ Cost } & \multicolumn{3}{|c|}{ Load Contribution } & \multicolumn{2}{|c|}{ Cost Inciease / Use } \\
\hline & & & & 5.50 & & & $\overline{0}$ & & 1 \\
\hline \multicolumn{10}{|l|}{ 四Price } \\
\hline 38 & 39 & 40 & - & 41 & - & 42 & & 3 & 44 \\
\hline$\$ 5.00$ & $\$ 5.00$ & & & & $\$ 8.00$ & $\$ 8.0$ & & $\$ 8.00$ & $\$ 5.00$ \\
\hline
\end{tabular}

Figure 4.4 - Validation scenario 4: Model settings 
The TIS price curve and resulting model output for scenario 4 is shown in Figure 4.5. During the TIS price event, the TIS price is shown at $\$ 8.00 / \mathrm{MWh}$ in intervals 40 through 43 . The model results demonstrate the correct model
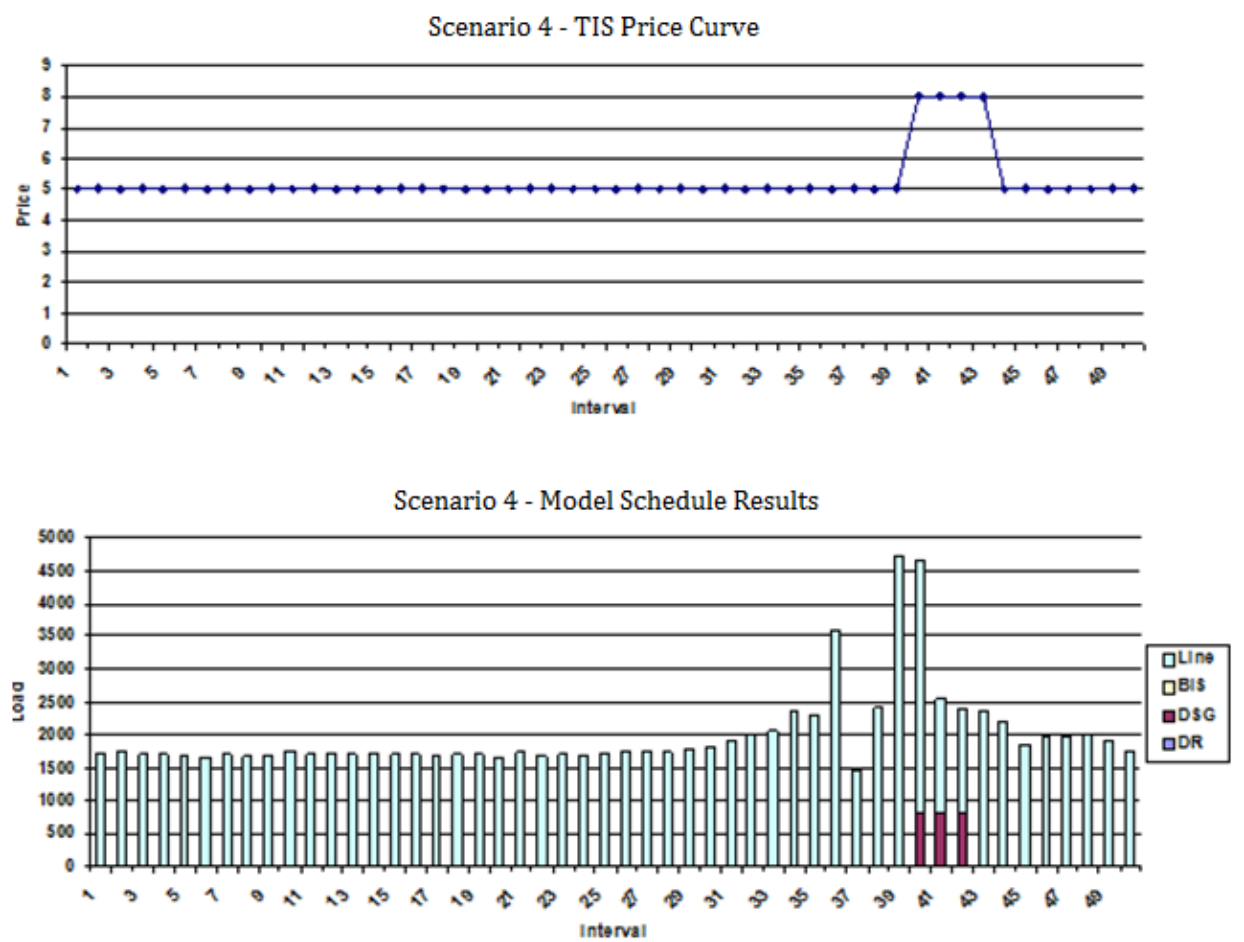

Figure 4.5 - Validation scenario 4: TIS price and model results

behavior, such that transmission supplied power is utilized for the dispatch over the entire schedule horizon with exception to the three intervals where $\boldsymbol{F}\left(P_{T}\right)$ exceeds the SGS agent dispatch price $\boldsymbol{F}\left(P_{S G S}\right)$. Further, the aggregate price increases of $\$ 1.00 /$ MWh per use surpass the transactive price following the third scheduled dispatch; thus, the DSG resource, originally priced at $\$ 5.50 / \mathrm{MWh}$, dispatches in interval 40 through 42 , where the final $\$ 1.00 / \mathrm{MWh}$ price increase finally displaces the resource at $\$ 8.50 / \mathrm{MWh}$ and transmission supplied power becomes the leastcost alternative in period 43. 
Scenario 5 moves from single resource dispatch to multiple agent dispatch. Here, each agent's price $\boldsymbol{F}\left(P_{S G S}\right)$ is set the same, and a single TIS price event is set to occur in only one interval. Scenario 5 agent setup is shown in Figure 4.6 along

\begin{tabular}{|c|c|c|c|c|c|}
\hline \multirow{2}{*}{$\begin{array}{l}\text { Agent } \\
S G S D R\end{array}$} & & & \multirow{2}{*}{$\begin{array}{l}\text { Cost } \\
55.50\end{array}$} & Load Contribution & Cost Inciease / Use \\
\hline & & & & $\sqrt{100}$ & $\longdiv { 1 }$ \\
\hline SGS DSG & & & $\$ 5.50$ & $\infty 00$ & 1 \\
\hline 565 615 & & & 55.50 & 200 & 1 \\
\hline \multicolumn{6}{|l|}{ 团 Price } \\
\hline 39 & . & 40 & * & 41 & 42 \\
\hline$\theta$ & $\$ 5.00$ & & $\$ 8.00$ & $\$ 5.00$ & $\$ 5.00$ \\
\hline
\end{tabular}

Figure 4.6 - Validation scenario 5: Model settings

with an excerpt of the TIS price table noting the price event at interval 40 at $\$ 8.00 /$ MWh up from $\$ 5.00 /$ MWh.

The TIS price curve and corresponding model schedule results are shown in Figure 4.7. The result reveals the correct model behavior, such that transmission
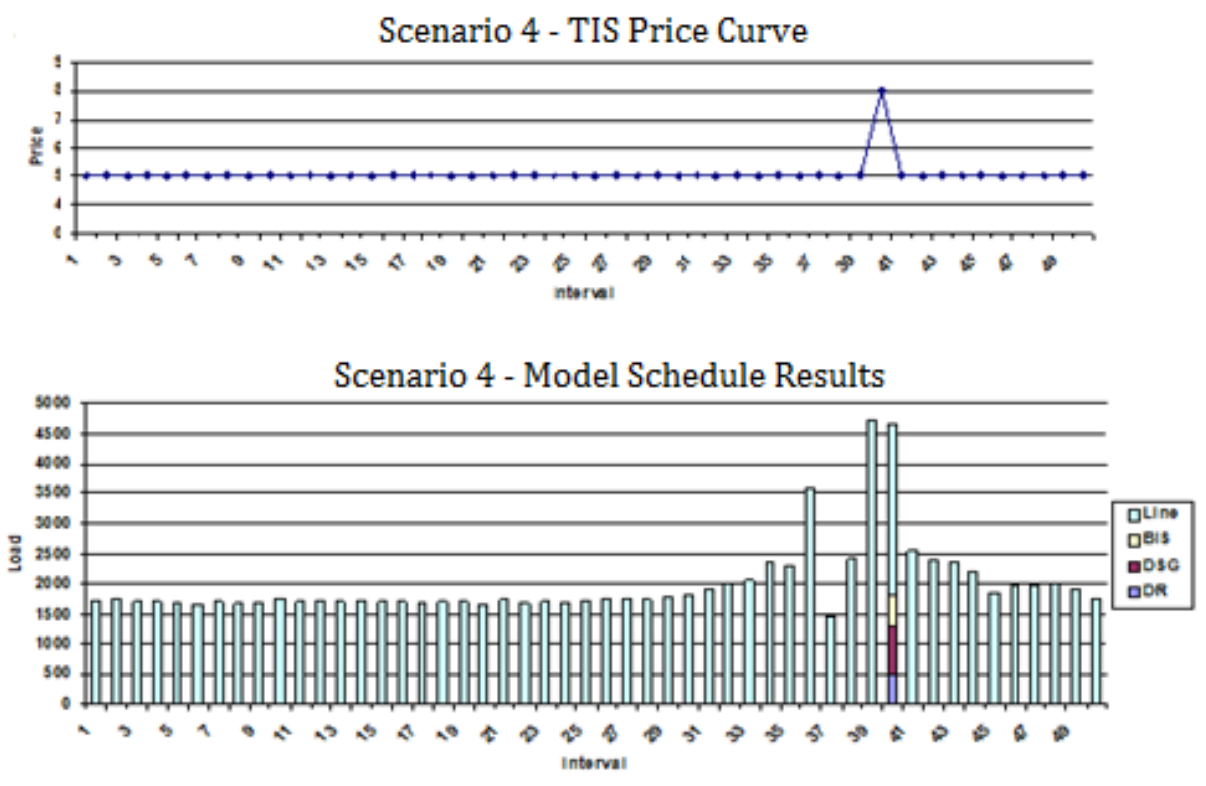

Figure 4.7 - Validation scenario 5: TIS price and model results 
supplied power is scheduled over the entire schedule horizon with exception to the one interval where the TIS price exceeds the SGS assets' dispatch price. All three SGS agents are shown scheduled within interval 40 where the TIS price event occurs, and each SGS resource thus contributes to the least-cost schedule.

Validation scenario 6 tests for dispatch with all available SGS assets with different initial prices. In this test, each agent is priced over the TIS for all but one interval with different prices among SGS resources. This test confirms the dispatch ranking of assets when multiple assets, but not all assets, may be economically efficient in lieu of transmission-supplied power. The SGS model settings are shown in Figure 4.8, including SGS asset variables and an excerpt of the TIS price curve showing the price event at interval 40.

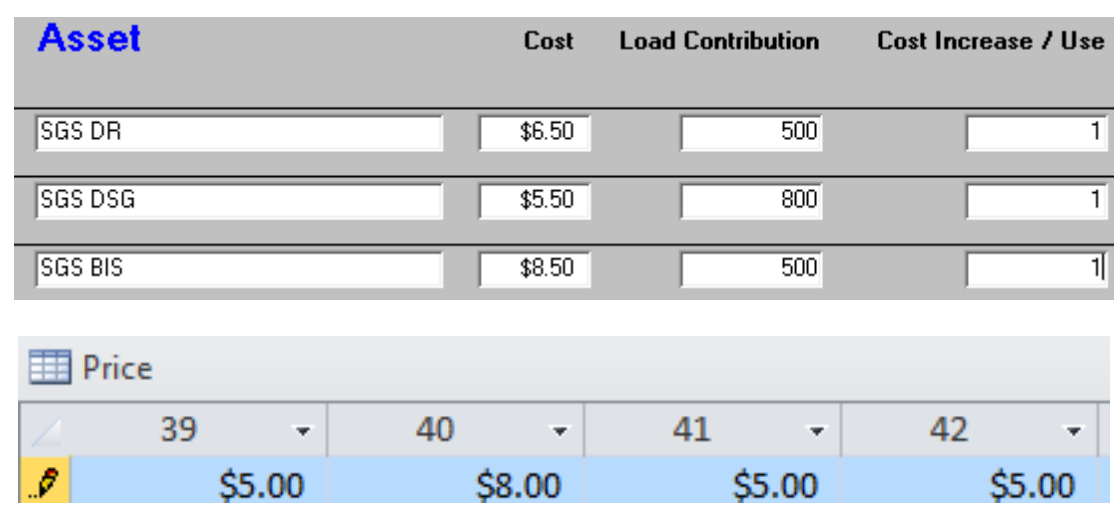

Figure 4.8 - Validation scenario 6: Model settings

Scenario 6 model results reveal the correct economic dispatch behavior, such that transmission-supplied power is utilized for the dispatch over the entire schedule horizon with exception to the TIS price event interval. The TIS price curve and the corresponding model output schedule is shown in Figure 4.9. Note where 
each agent price $\boldsymbol{F}\left(P_{S G S}\right)$ is less than the environment price, each agent dispatches. Notably, the BIS resource does not dispatch, since its price at that interval is $\$ 8.50 /$ MWh compared to the TIS price at $\$ 8.00 / \mathrm{MWh}$.
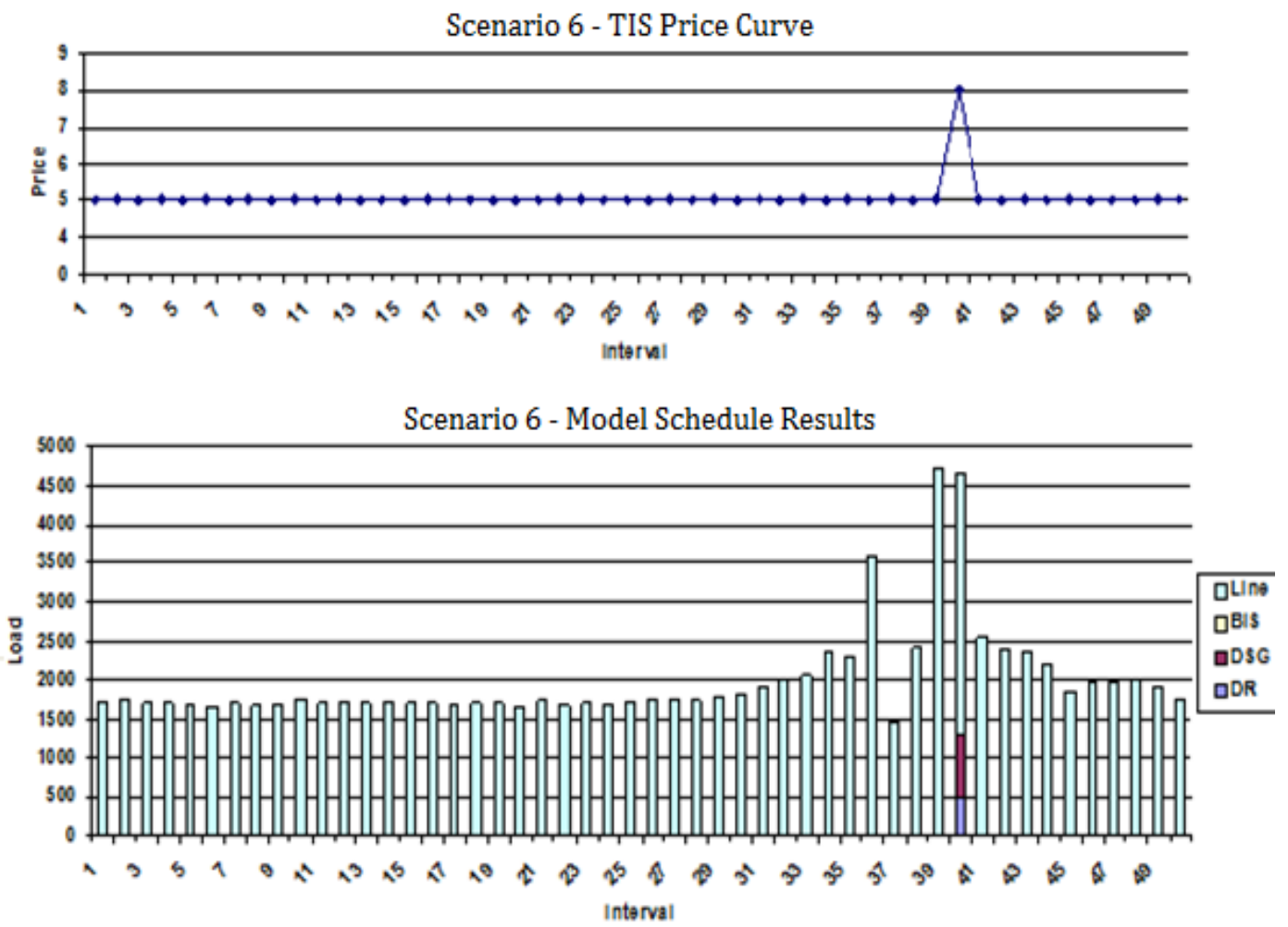

Figure 4.9 - Validation scenario 6: TIS price and model results

Scenario 7 tests all SGS assets with different dispatch prices $\boldsymbol{F}\left(P_{S G S}\right)$, with a single TIS price event occurring over 26 intervals having a characteristically slow positive rate of change, followed by a sudden TIS price decrease. This test should confirm the dispatch ranking of assets when multiple assets, but not all assets over time, may be economically efficient. The SGS price function is set to increase $\$ 1.00 / \mathrm{MWh}$ for each dispatch, while the TIS price increases only $\$ 0.50 / \mathrm{MWh}$ per 
interval. The SGS agent setup and a graph of the transactive price table are shown in Figure 4.10.

\begin{tabular}{|c|c|c|c|}
\hline Agent & Cost & Load Contribution & Cost Increase / Use \\
\hline SGS DR & $\$ 5.50$ & 100 & 1 \\
\hline SGS DSG & $\$ 6.50$ & 800 & 1 \\
\hline SGS BIS & $\$ 8.50$ & 200 & $\overline{1}$ \\
\hline
\end{tabular}

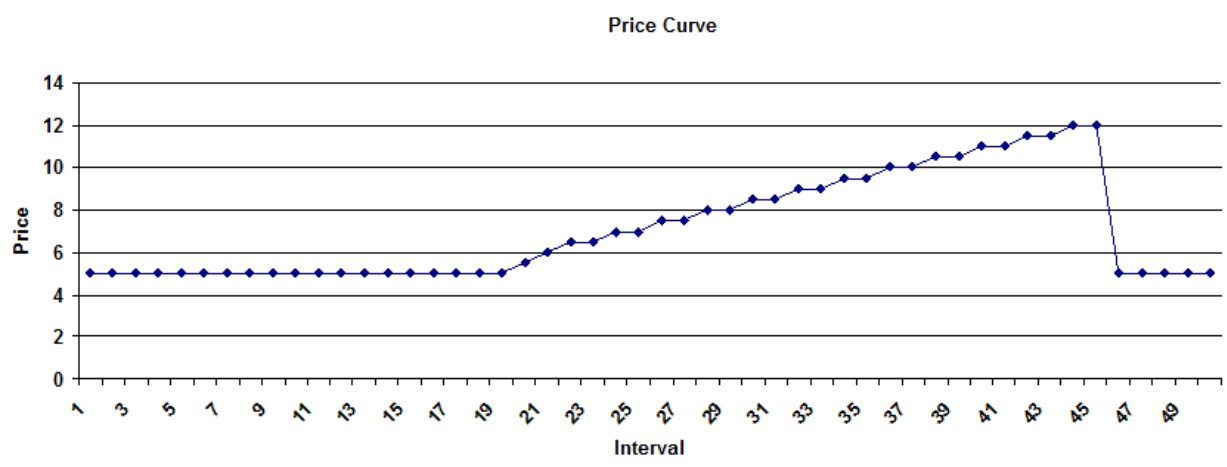

Figure 4.10 - Validation scenario 7: Model settings

The expected model output is an on/off dispatch pattern based on the following:

a. Initial dispatch behavior occurs as each SGS resource becomes efficient;

b. Dispatch turns off when scarcity price increases to exceed $\boldsymbol{F}\left(P_{T}\right)$;

c. Dispatch turns on again as the transactive price increase exceeds the scarcity charge increase.

The TIS price curve and the corresponding model output are shown in Figure 4.11. The model output demonstrates the expected behavior, such that transmission supplied power $P_{T}$ is utilized over the entire schedule horizon with exception to the 
intervals where transactive price $\boldsymbol{F}\left(P_{T}\right)$ exceeds each SGS agent dispatch price $\boldsymbol{F}\left(P_{S G S}\right)$. Further, SGS resources correctly dispatch according to their price. The
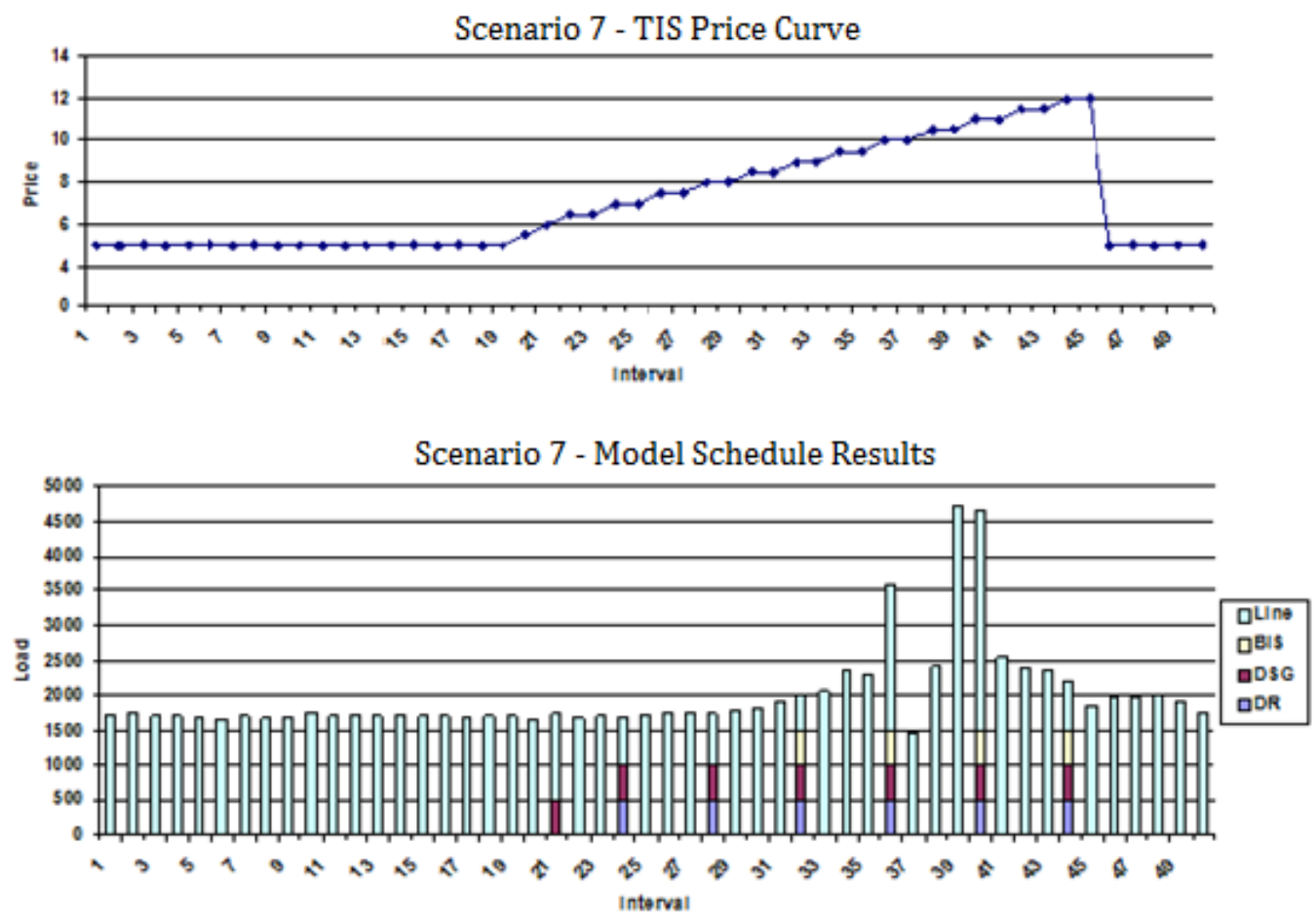

Figure 4.11 - Validation scenario 7: TIS price and model results increase applied to each SGS resource price after each dispatch does affect asset behavior, and interrupts dispatch correctly. Finally, as the agent price $\boldsymbol{F}\left(P_{S G S}\right)$ becomes efficient again, another dispatch is scheduled at the higher TIS price.

Validation scenario 8 tests the model for its response to the most complex scheduling horizon including all the features of interest to this thesis:

- changing TIS prices over time at different rates of change;

- a mix of both short and long duration TIS events;

- use of all available SGS assets with different SGS asset prices and varying rates of SGS price function change; and 
- load balancing constraints compared to available generation resources.

Thus, scenario 8 contains multiple dispatch opportunities where the TIS price $\boldsymbol{F}\left(P_{T}\right)$ is the least-cost alternative to SGS resource prices across some but not all intervals. Load is also limited, testing model response to the power balance constraint pertaining to Equation 1.

The resulting output is shown in Figure 4.12, demonstrating the expected model response. Transmission supplied power $P_{T}$ is utilized across the entire
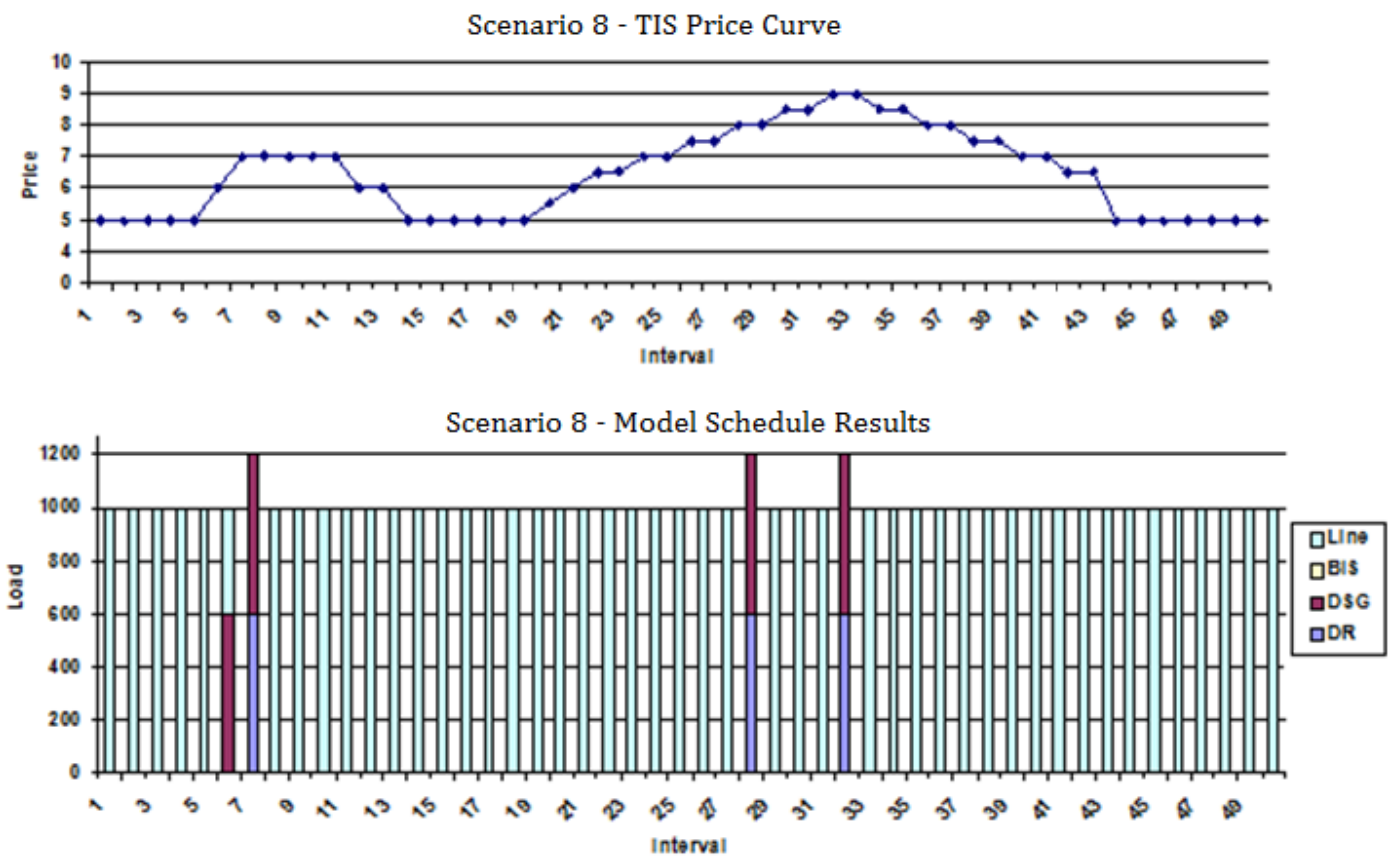

Figure 4.12 - Validation scenario 8: TIS price and model results

schedule horizon with exception to the intervals where $\boldsymbol{F}\left(P_{T}\right)$ extends above each SGS agent dispatch price $\boldsymbol{F}\left(P_{S G S}\right)$. Also, note the two TIS price events and the correct difference in model response. Finally, due to the limited loads, the least efficient 
dispatch is ignored (the BIS agent); even though the BIS agent was an economically attractive alternative, it was the least efficient among other SGS resources, therefore, it was not scheduled. Notably, the model could be programmed to allow strategies calling for all economically efficient resources to dispatch regardless of the load balance, in order to export power to the transmission grid.

\subsubsection{Model performance}

Performance metrics were gathered as model validation tests were completed. Using the Visual Basic timer function, the processing time for the threaded application to complete the simulation was captured. The model run speeds for each testing scenario are shown in Figure 4.13.

\begin{tabular}{c|r|r|r|r|r|r}
\cline { 2 - 6 } Scenario & \multicolumn{1}{l|}{ Run 1 } & \multicolumn{1}{l|}{ Run 2 } & \multicolumn{1}{l|}{ Run 3 } & \multicolumn{1}{l|}{ Run 4 } & \multicolumn{1}{l}{ Run 5 } & \multicolumn{1}{l}{ Average (sec) } \\
\hline 1 & 0.02 & 0.02 & 0.02 & 0.02 & 0.02 & 0.02 \\
\hline 2 & 0.02 & 0.02 & 0.03 & 0.02 & 0.02 & 0.022 \\
\hline 3 & 0.03 & 0.02 & 0.03 & 0.03 & 0.02 & 0.026 \\
\hline 4 & 0.03 & 0.02 & 0.02 & 0.03 & 0.02 & 0.024 \\
\hline 5 & 0.02 & 0.04 & 0.03 & 0.02 & 0.03 & 0.028 \\
\hline 6 & 0.02 & 0.02 & 0.03 & 0.03 & 0.04 & 0.028 \\
\hline 7 & 0.03 & 0.03 & 0.04 & 0.04 & 0.03 & 0.034 \\
\hline 8 & 0.04 & 0.04 & 0.04 & 0.04 & 0.04 & 0.04 \\
\hline
\end{tabular}

Figure 4.13 - Model performance metrics

Time is reported to the nearest 0.01 seconds due to the functional limits of the timer function. Notably, the simulation performs well, finishing on average in about a third of a second, well under the goal of achieving 4 seconds or less for a resulting model dispatch schedule. 
A graph of run speed by validation scenario is shown in Figure 4.14.

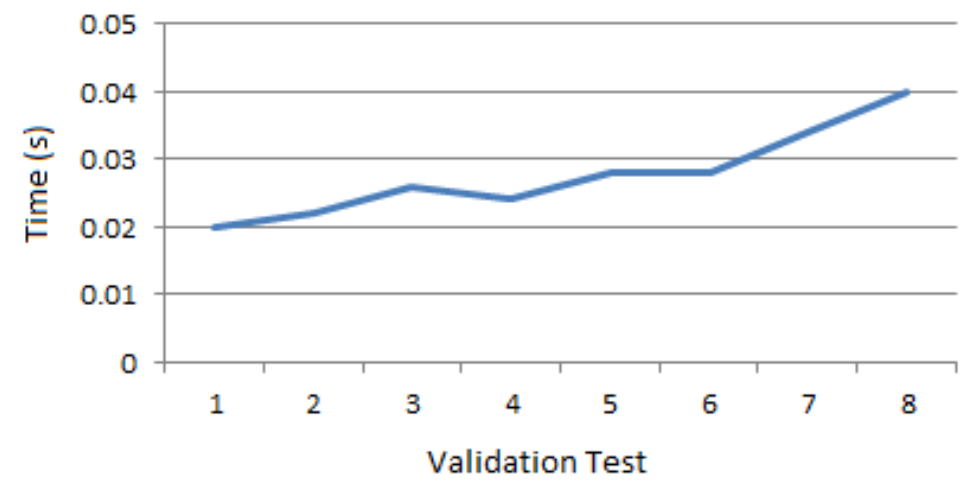

Figure 4.14 - Model performance: Simulation speed by validation test scenario

Model performance in terms of maximum processor percentage used during each test was also captured for each validation test. Processor performance is shown in Figure 4.15.

\begin{tabular}{|c|r|r|r|r|r|r|}
\hline \multirow{2}{*}{ Scenario } & \multicolumn{1}{l|}{ Run 1 } & \multicolumn{1}{l|}{ Run 2 } & \multicolumn{1}{l|}{ Run 3 } & \multicolumn{1}{l|}{ Run 4 } & \multicolumn{1}{l|}{ Run 5 } & \multicolumn{1}{l|}{ Average( \% ) } \\
\hline 1 & 13.07 & 10.74 & 13.08 & 11.47 & 12.5 & 12.172 \\
\hline 2 & 11.56 & 11.51 & 13.64 & 12.53 & 11.86 & 12.22 \\
\hline 3 & 12.13 & 14.06 & 11.13 & 14.06 & 12.69 & 12.814 \\
\hline 4 & 13.32 & 16.38 & 11.32 & 11.45 & 12.3 & 12.954 \\
\hline 5 & 12.5 & 15.82 & 12.69 & 12.5 & 12.89 & 13.28 \\
\hline 6 & 13.67 & 12.69 & 14.25 & 14.84 & 16.01 & 14.29 \\
\hline 7 & 16.1 & 14.84 & 16.99 & 17.38 & 14.42 & 15.95 \\
\hline 8 & 16.41 & 16.79 & 15.9 & 16.21 & 14.86 & 16.03 \\
\hline
\end{tabular}

Figure 4.15 - Model performance: CPU usage metrics by validation test

CPU usage is shown to increase slightly with more complex validation tests, but it is notable that this will also vary given different processor speeds and configurations, as well as using other application environments to host the simulation. The simulation is executed using Visual Basic within Microsoft Access. Using C\#, C++, or Java would have different results, just as running the application on Microsoft's SQL 
Server or another more advanced database engine could likewise improve performance.

Scaling the model is also of interest, especially for transactive energy applications with many SGS resources under management. In [12] and [71], four resources are managed by their respective transactive dispatch applications, just as it is tested in this thesis in scenarios 4 through 8 . However, a smart grid could be expected to have hundreds - if not thousands-of resources aggregated into many dispatchable virtual power plants. In order to examine such a portfolio of SGS resources, the model is tested using incremental increases of three resources for each test run, up to forty-eight SGS resources. The resulting model performance testing and calculated (linear) trendline are shown in Figure 4.6. Assuming the trend for scaling remains linear, approximately 1,500 SGS resources (or aggregated VPP) could be scheduled for transactive market participation in less than 4 seconds.

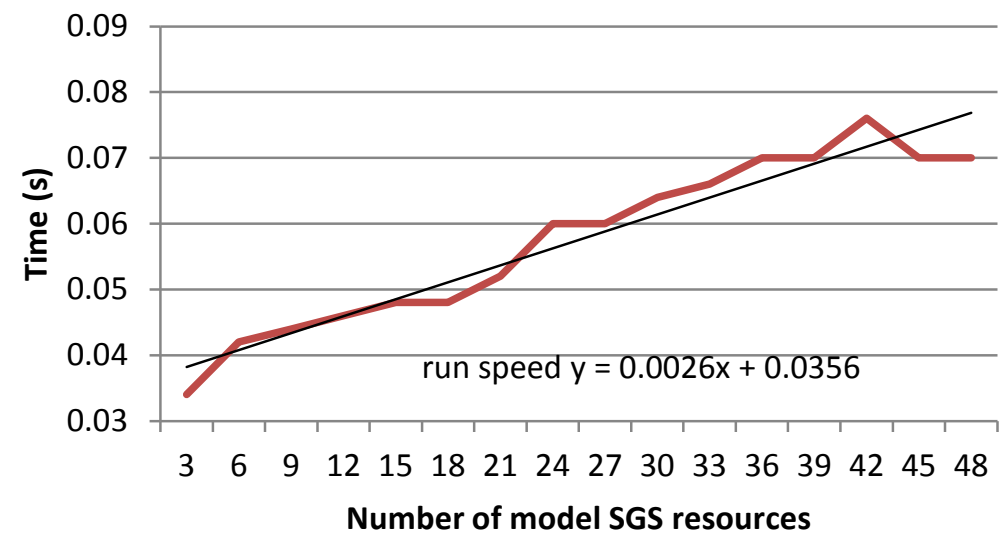

Figure 4.16 - Model performance: Application scaling 


\section{Discussion}

This thesis demonstrates that global time-independent agent-based modeling may be successfully applied to transactive system economic dispatch and schedule forecasting. The model, applied conservatively here, has shown potential as a valuable tool for fast dispatch scheduling, but only scratches the surface of possibilities for the method demonstrated. Planning to explore this approach for further potential, I expect to show value for a wide array of other complex interactions between agents, specifically for electrical control applications. The approach here - using agents with their unique communication method through forecasted time periods-represents a powerful tool that can be used to develop control components for a wide variety of applications. Ideally, agents might represent anything that may change through time that features an action depending on a constraint —or multiple constraints — where individual agents are assigned each variable of interest across time. This is critical because the model approach relies on exchanging limited information across time between agents, decreasing the total information required to produce efficient solutions. In summary, it is demonstrated that the concept of temporal agents representing the same resource is a new approach that allows agents to quickly identify which times are of interest for a particular scheduling horizon, unlike most approaches which march through time sequentially.

Further research is needed to explore the following: 
- interconnect models vs. microgrid model potential (scaling the approach to thousands of resources);

- exploring generation agents to represent facilities with intermittent generation (renewables) or other probabilistic factors over time;

- adding environmental variables to represent network and other system constraints;

- adding agents that model distribution switch automation or other substation related actions which may impact responsive control; and - adding agents to model distribution lines and other physical system characteristics.

A simulator based on the principles demonstrated here might be used in a distributed computing environment (e.g., in a microgrid substation) allowing ESP to take one step closer to SGS resource automation and transactive control implementation. Moving forward with research from this thesis will be a directed effort in this regard, introducing the potential for new advancements in control that satisfy the needs of the next evolution of smart grid systems and their integration with the "Internet of things." 


\section{Bibliography}

[1] U.S. National Institute of Standards, "NIST and the Smart Grid," U.S. Department of Commerce, 15 November 2010. [Online]. Available: http://www.nist.gov/smartgrid/nistandsmartgrid.cfm. [Accessed 1 July 2014].

[2] S. Chandler, "On the nature of smart grid and interoperability: civilization and its discontents," in Innotech Smart Grid Oregon Proceedings, Portland, 2011.

[3] J. Momoh, "Fundamentals of analysis and computation for the Smart Grid," in Power and Energy Society General Meeting, 2010 IEEE, Minneapolis, 2010.

[4] X. Fang et al. "Smart Grid - The New and Improved Power Grid: A Survey," Communications Surveys \& Tutorials, IEEE, vol. 14, no. 4, pp. 944-980, 2012.

[5] W. Wang, Y. Xu, and M. Khanna, "A survey on the communication architectures in smart grid," Computer Networks, vol. 55, no. 15, pp. 3604-3629, 2011.

[6] EPRI, “EPRI Advanced Metering Infrastructure,” 1 February 2007. [Online]. Available: https://www.ferc.gov/EventCalendar/Files/20070423091846-EPRI\%20\%20Advanced\%20Metering.pdf. [Accessed 1 July 2014].

[7] IESO Ontario, "Smart Grid Principles," 9 February 2010. [Online]. Available: https://ieso-public.sharepoint.com/Documents/smart_grid/materials/20100209/ MEI\%20Smart\%20Grid\%20Principles\%2020100208.pdf. [Accessed 28 June 2014].

[8] International Electrotechnical Commission, "IEC 61850: Power Utility Automation Standard," International Electrotechnical Commission, Geneva, 2014.

[9] International Electrotechnical Commission, "IEC-61968: Common Information Model for Distribution Management," International Electrotechnical Commission, Geneva, 2014.

[10] National Institute of Standards, "Smart Grid Conceptual Model," 2014. [Online]. Available: www.nist.gov/smartgrid/upload/NIST-SP-1108r3.pdf. [Accessed 30 Dec 2014].

[11] S. Chandler et al., "Smart Grid Dispatch Optimization Control Techniques for Transactive Energy Systems," in Technologies for Sustainability (SusTech), 2014 2nd IEEE Conference on, Portland, 2014.

[12] S. Chandler and J. Hughes, "Smart grid distribution prediction and control using computational intelligence," in Technologies for Sustainability (SusTech), 2013 1st IEEE Conference on, Portland, 2013. 
[13] S. Amin and B. Wollenberg, "Toward a smart grid: power delivery for the $21^{\text {st }}$ century," Power and Energy Magazine, IEEE, vol. 3, no. 5, pp. 34-41, SeptemberOctober 2005.

[14] P. Christensen, "21 $1^{\text {st }}$ Century Grid: Deploying New Technologies," in National Conference of State Legislators Proceedings, Washington, DC, 2013.

[15] T. Flick and J. Morehouse, "Securing the Smart Grid: Next Generation Power Grid Security," Burlington: Elsevier, 2010.

[16] G. Venayagamoorthy, "Potentials and promises of computational intelligence for smart grids," in Power \& Energy Society General Meeting Proceedings, Calgary, 2009.

[17] H. He, "Toward a Smart Grid: Integration of computational intelligence into Power Grid," in Proceedings Neural Networks (IJCNN), Barcelona, 2010.

[18] P. Werbos, "Computational Intelligence for the Smart Grid-History, Challenges, and Opportunities," Computational Intelligence Magazine, IEEE, pp. 14-21, August 2011.

[19] D. Park et al., "Electric Load Forecasting Using an Artificial Neural Network," IEEE Transactions on Power Systems, vol. 6, no. 2, pp. 442-449, 1991.

[20] I. Moghram and S. Rahman, "Analysis and evaluation of five short-term load forecasting techniques," IEEE Transactions on Power Systems, vol. 4, no. 4, pp. 14841491, 1989.

[21] H. M. AlRashidi, "Applications of computational intelligence techniques for solving the revived optimal power flow problem," Electric Power Systems Research, vol. 79, no. 4, pp. 694-702, 2009.

[22] L. Phillips et al., "Agent basedcontrol of distributed infrastructure resources - Report 2005-7937," Sandia National Laboratory, Livermore, 2006.

[23] G. Venayagamoorthy, "Potentials and promises of computational intelligence for smart grids," in Power \& Energy Society General Meeting, IEEE PES09, Calgary, 2009.

[24] M. Hawks, Interviewee, Manager, Real-time power operations. [Interview]. 14 July 2008.

[25] U.S. Energy Information Agency, "Electric generator dispatch depends on system demand and the relative cost of operation," 17 August 2012. [Online]. Available: http://www.eia.gov/todayinenergy/detail.cfm?id=7590. [Accessed 2 July 2014].

[26] G. Lendaris, "Adaptive dynamic programming approach to experience-based systems identification and control," Neural Networks, vol. 22, no. 5, pp. 822-832, 2009. 
[27] A. Dimeas and N. Hatziargyriou, "Operation of a multiagent system for microgrid control," IEEE Transactions on Power Systems, vol. 20, no. 3, pp. 1447-1455, 2005.

[28] H. Akkermans, F. Ygge, and R. Gustavsson, "Homebots: Intelligent decentralized control for energy management," in Proceedings, International Symposium on the Management of Industrial and Corporate Knowledge, Rotterdam, 1996.

[29] C. Lozano and D. Ramos, "Multi-agent based tool for the analysis of the Colombian electricity market," in Electric Utility Deregulation and Restructuring and Power Technologies (DRPT), Weihai, 2011.

[30] J. Sun and L. Tesfatsion, "Dynamic testing of wholesale power market designs: An open-source agent basedframework," Computational Economics, vol. 30, no. 3, pp. 291-327, 2007.

[31] 0. Browne, S. Poletti, and D. Young, "Simulating Market Power in the New Zealand Electricity Market,” New Zealand Economic Papers, vol. 46, no. 1, pp. 35-50, 2012.

[32] C. Colson and M. Nehrir, "Agent basedpower management of microgrids including renewable energy power generation," in Power and Energy Society General Meeting, 2011 IEEE, San Diego, 2011.

[33] S. Huang, "Enhancement of hydroelectric generation scheduling using ant colony system based optimization approaches," IEEE Transactions on Energy Conversion, vol. 16, no. 3, pp. 296-301, 2001.

[34] M. Kouluri and R. Pandey, "Intelligent Agent Based Micro grid Control," in Intelligent Agent and Multi-Agent Systems (IAMA), Chennai, 2011.

[35] Z. Ming et al., "A multi-agent based dispatching operation instructing system in electric power systems," in Power Engineering Society General Meeting, 2003, IEEE Volume:1, Toronto, 2003.

[36] F. Eddy and H. B. Gooi, "Multi-agent system for optimization of microgrids," in Power Electronics and ECCE Asia (ICPE \& ECCE), Jeju, 2011.

[37] M. Osborne, Interviewee, Manager - PGE Distributed Standby Generation and Demand Response Programs. [Interview]. 30 January 2013.

[38] Hong-Tzer Yang et al., "Identification of ARMAX model for short term load forecasting: an evolutionary programming approach," in Power Industry Computer Application Conference Proceedings, Salt Lake City, 1995.

[39] D. Park et al., "Electric load forecasting using an artificial neural network," IEEE Transactions on Power Systems, vol. 6, no. 2, pp. 442-449, 1991. 
[40] C. Lin and G. Viviani, "Hierarchical Economic Dispatch for Piecewise Quadratic Cost Functions," IEEE Transactions on Power Apparatus and Systems, vols. PAS-103, no. 6, pp. 1170-1175, 1984.

[41] J. Cai et al., "A multi-objective chaotic particle swarm optimization for environmental/economic dispatch," Energy Conversion and Management, vol. 50, no. 5, pp. 1318-1325, 2009.

[42] J. Talaq and M. El-Hawary, "A summary of environmental/economic dispatch algorithms," IEEE Transactions on Power Systems, vol. 9, no. 3, pp. 1508-1516, 1994.

[43] S. V. Vadari and J. D. Hammerly, "New faces and functions in a competitive market," IEEE Computer Applications in Power, vol. 10, no. 1, pp. 47-52, 1997.

[44] H. Chao et al., "Flow-based transmission rights and congestion management," The Electricity Journal, vol. 13, no. 8, pp. 38-58, 2000.

[45] R. C. Hemphill, M. E. Meitzen, and P. E. Schoech, "Incentive regulation in network industries: Experience and prospects in the US telecommunications, electricity, and natural gas industries," Review of Network Economics, vol. 2, no. 4, pp. 316-337, December 2003.

[46] J. Momoh, Smart Grid Findamentals of Design and Analysis, Hoboken: Wiley IEEE Press, 2012.

[47] M. Lijesen, “The real-time price elasticity of electricity," Energy Economics, vol. 29, no. 2, pp. 249-258, 2007.

[48] M. Molina, "The Best Value for America's Energy Dollar:A National Review of the Cost of Utility Energy Efficiency Programs," American Council for an Energy Efficient Economy, Washington, DC, 2014.

[49] AEP, “AEP Ohio gridSMART Demonstration Project,” [Online]. Available: http://www.gridsmartohio.com/. [Accessed 20 July 2014].

[50] Batelle Memorial Institute - Pacific Northwest National Laboratory, "Pacific Northwest Smart Grid Demonstration Project,” Batelle Memorial Institute, 2010. [Online]. Available: http://www.pnwsmartgrid.org/. [Accessed 20 July 2014].

[51] “Korea's Smart Grid Test-Bed Overview," [Online]. Available: http://www.smartgrid.or.kr/10eng3-1.php. [Accessed 20 July 2014].

[52] P. Joskow, "Transmission policy in the United States," Utilities Policy, vol. 13, no. 2, pp. 95-115, 2005. 
[53] K. Miller, Interviewee, Manager - Fundamental Analysis, Portland General Electric. [Interview]. 15 March 2010.

[54] C. Marnay et al., "Los Angeles Air Force Base Vehicle to Grid Pilot Project Report LBNL-6154E,” LBNL, Berkeley, 2013.

[55] D. Hammerstrom et al., "Standardization of a hierarchical transactive control system," in Proceedings Grid-Interop 2009, Denver, 2009.

[56] M. Piette et al., "Automated Measurement and Signaling Systems for the Transactional Network - Report LBNL-6611E,” Lawrence Berkeley National Laboratory, Berkely, 2013.

[57] K. LaCommare and J. Eto, "Understanding the Cost of Power Interruptions to U.S.Electricity Consumers," Ernest Orlando Lawrence Berkeley National Laboratory, Berkeley, 2004.

[58] G. Herring, "Wellinghoff to utilities: Time to rethink your business model," GreenBiz, Oakland, 2014.

[59] A. Borshchev and A. Filippov, "From System Dynamics and Discrete Event to Practical Agent Based Modeling: Reasons, Techniques and Tools," in System Dynamics Society, $22^{\text {nd }}$ International Conference, Oxford, 2004.

[60] J. Epstein et al., "A Distributed Platform for Global-Scale Agent basedModels of Disease Transmission,” TOMACS, vol. 1, no. 22, 2011.

[61] C. Macal and M. North, "Tutorial on Agent Based Modeling and Simualtion," in IEEE Winter Simulation Conference, Orlando, 2005.

[62] J. Epstein and R. Axtell, Growing Artificial Societies, Washington: Brookings Institution Press, 1996.

[63] J. Holland and J. Miller, "Artificial Adaptive Agents in Economic Theory," American Economic Review, vol. 81, no. 2, pp. 365-370, 1991.

[64] S. Balani, "Smart Grid Technologies for Efficiency Improvement of Integrated Industrial Electrical Systems," University of New Orleans, New Orleans, 2011.

[65] V. Gungor et al. "Smart Grid Technologies: Communication Technologies and Standards," Bahcesehir Univerisity, Istanbul, 2011.

[66] D. Hammerstrom et al., "Pacific Northwest GridWise ${ }^{\mathrm{TM}}$ Testbed Projects Part I Olympic Peninsula Project - Report PNNL-17167," Pacific Northwest National Laboratory, Richland, 2007. 
[67] F. Maturana et al., "Simulation based environment for modeling distributed agents for smart grid energy management," in Emerging Technologies \& Factory Automation (ETFA), 2011 IEEE 16 th Conference on, Toulouse, 2011.

[68] J. Taft and P. DeMartini, "Ultra Large Scale Power System Control Architecture," Cisco, San Jose, 2012.

[69] J. G. Hughes and G. G. Lendaris, "Explorations on system identification via higher-level application of Adaptive-Critic Approximate Dynamic Programming," in Neural Networks (IJCNN) 2011, San Jose, 2011.

[70] F. Delea and J. Casazza, Understanding Electric Power Systems: An Overview of the Technology, the Marketplace, and Government Regulation. Hoboken, NJ: John Wiley \& Sons, 2011.

[71] A. Hoke et al., "Look-ahead economic dispatch of microgrids with energy storage, using linear programming," in Technologies for Sustainability (SusTech), 2013 1st IEEE Conference on, Portland, 2013. 


\section{Appendix: Validation Scenario Feature Matrix}

\begin{tabular}{|c|c|c|c|c|c|c|c|c|c|c|c|c|}
\hline Scenario & $\begin{array}{l}\text { No TIS } \\
\text { Events }\end{array}$ & $\begin{array}{l}\text { TIS Change } \\
\text { Fast }\end{array}$ & $\begin{array}{l}\text { TIS Change } \\
\text { Slow }\end{array}$ & $\begin{array}{l}\text { Single TIS } \\
\text { Event }\end{array}$ & $\begin{array}{l}\text { Muliple TIS } \\
\text { Events }\end{array}$ & $\begin{array}{l}\text { TIS Event } \\
\text { Durafon } \\
\text { Short }\end{array}$ & $\begin{array}{l}\text { TIS Event } \\
\text { Durafion } \\
\text { Long }\end{array}$ & $\begin{array}{l}\text { Single SGS } \\
\text { Asset } \\
\text { Available }\end{array}$ & \begin{tabular}{|l|} 
Muliple SGS \\
Assets \\
Available
\end{tabular} & \begin{tabular}{|l} 
SGS Cost \\
Funcion \\
Change \\
Slow
\end{tabular} & \begin{tabular}{|l} 
SGS Cost \\
Funcion \\
Change \\
Fast \\
\end{tabular} & \begin{tabular}{|l} 
Dynamic \\
Load \\
Constraints
\end{tabular} \\
\hline 1 & • & & & & & & & & • & & & \\
\hline 2 & & - & & - & & - & & • & & • & & \\
\hline 3 & & & - & - & & - & & • & & & - & \\
\hline 4 & & • & & - & & & - & • & & • & & \\
\hline 5 & & • & & • & & • & & & • & & • & \\
\hline 6 & & - & & & - & - & & & - & & - & \\
\hline 7 & & & - & - & & & - & & • & & • & \\
\hline 8 & & • & • & & • & • & • & & • & • & • & • \\
\hline
\end{tabular}

